\title{
A Model of the Ocean Overturning Circulation with Two Closed Basins and a Reentrant Channel
}

\author{
RAFFAELE FERRARI \\ Massachusetts Institute of Technology, Cambridge, Massachusetts \\ LOUIS-PHILIPPE NADEAU \\ Université du Québec Á Rimouski, Rimouski, Quebec, Canada \\ DAVID P. MARSHALL \\ University of Oxford, Oxford, United Kingdom \\ LESLEy C. AlLison \\ Met Office Hadley Centre, Exeter, United Kingdom \\ HELEN L. JOHNSON \\ University of Oxford, Oxford, United Kingdom
}

(Manuscript received 3 October 2016, in final form 4 October 2017)

\begin{abstract}
Zonally averaged models of the ocean overturning circulation miss important zonal exchanges of waters between the Atlantic and Indo-Pacific Oceans. A two-layer, two-basin model that accounts for these exchanges is introduced and suggests that in the present-day climate the overturning circulation is best described as the combination of three circulations: an adiabatic overturning circulation in the Atlantic Ocean associated with transformation of intermediate to deep waters in the north, a diabatic overturning circulation in the IndoPacific Ocean associated with transformation of abyssal to deep waters by mixing, and an interbasin circulation that exchanges waters geostrophically between the two oceans through the Southern Ocean. These results are supported both by theoretical analysis of the two-layer, two-basin model and by numerical simulations of a three-dimensional ocean model.
\end{abstract}

\section{Introduction}

The global ocean overturning circulation is a key element of Earth's climate system and the ocean biogeochemical cycles through its transport of heat, carbon, and nutrients both across latitudes and from one ocean basin to another through the Southern Ocean. Most idealized models and theories of the overturning circulation focus on the zonally averaged transports and ignore the zonal transports. Here we extend those models to capture the zonal interbasin exchanges through the Southern Ocean. Our model illustrates that the zonal interbasin transports are crucial to properly interpret

Corresponding author: Raffaele Ferrari, rferrari@mit.edu the ocean overturning circulation and its changes in different climates.

In the textbook zonally averaged perspective, the present-day ocean overturning is characterized by two distinct overturning cells stacked on top of each other (e.g., Lumpkin and Speer 2007; Marshall and Speer 2012). The upper cell consists of waters sinking in the North Atlantic, which then flow along isopycnals toward the Southern Hemisphere where they are pulled to the surface by the wind stress blowing over the Southern Ocean. Once at the surface, these dense waters appear to be transformed into lighter intermediate waters by surface heating and precipitation, and flow back to the North Atlantic, thereby closing the upper overturning cell. The lower cell is instead fueled by deep convection 


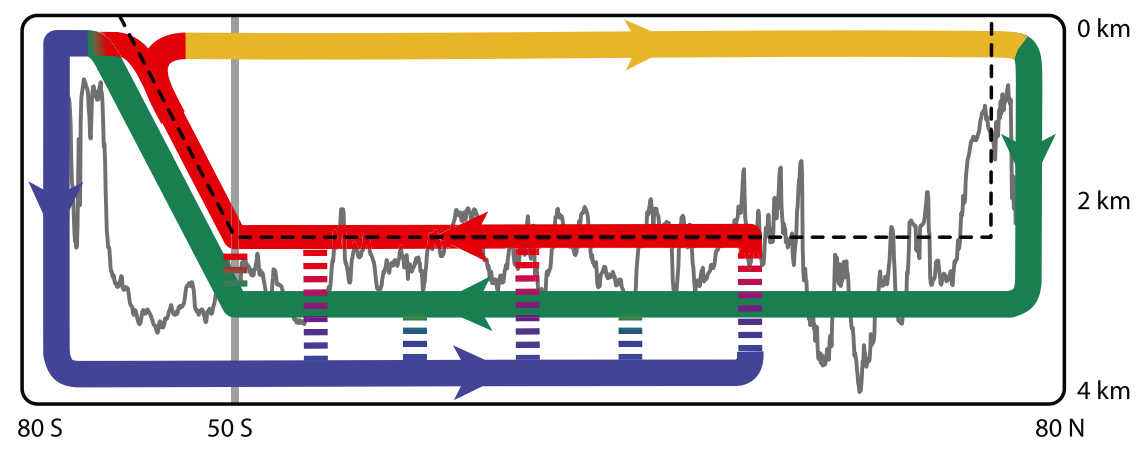

FIG. 1. Schematic of the present-day overturning circulation in a two-dimensional plane adapted from Talley (2013) and Ferrari et al. (2014). The ribbons represent the pathways of the major water masses in a depth-latitude plane; blue is AABW, green is NADW, red are IDW and PDW, and orange is Antarctic Intermediate Waters. The dashed vertical lines represent diapycnal mixing-driven upwelling of AABW into NADW and IDW/PDW, respectively. The dashed black line represents the isopycnal that separates deep and intermediate waters. The ragged gray line is the crest of the main bathymetric features of the Pacific and Indian Ocean basins: diapycnal mixing is enhanced below this line. The fact that the ribbons overlap is an indication of the fact that the flow cannot be described by a streamfunction in a two-dimensional plane; there are important interbasin exchanges.

around Antarctica and generates the densest waters that fill the bottom of all oceans. These dense waters are slowly transformed into lighter waters by diapycnal mixing in the lower overturning ocean basins, rise to about 2000-m depth, and flow back to the Southern Ocean, where they are also pulled to the surface by the Southern Hemisphere westerlies along isopycnals just below the upper cell. Once at the surface, these waters are supposedly transformed into denser waters by cooling and brine rejection under sea ice, and sink into the abyss closing the deep cell loop.

Observational oceanographers have long cautioned that the zonally averaged perspective is incomplete as it misses important interbasin exchanges (Schmitz 1995; Lumpkin and Speer 2007). Most recently Talley (2013) pointed out that the very idea that there are two separate cells is an artifact of taking a zonal average. Her analysis of water mass properties shows that most of the North Atlantic Deep Water (NADW), which fuels the upper cell in the high latitudes of the North Atlantic, is transformed into denser Antarctic Bottom Water (AABW) once it resurfaces in the Southern Ocean, contrary to the zonally averaged view that would have it fully transformed into lighter intermediate waters. Once converted into AABW, the waters fill the bottom of the Indo-Pacific Ocean, where they are transformed into lighter Indian Deep Water (IDW) and Pacific Deep Water (PDW) by turbulent diapycnal mixing. These waters then come to the surface around Antarctica, where they are transformed into intermediate waters and return to the North Atlantic. While what fraction of NADW is transformed into intermediate waters versus $\mathrm{AABW}$ remains uncertain, it is quite clear that the overturning circulation is best described as an intertwined loop that spans both the Atlantic and Indo-Pacific Oceans as sketched in Fig. 1.

Ferrari et al. (2014) pointed out that the present-day overturning loop that spans all oceans likely split into two separate cells during glacial climates. Thus, the common picture of an upper and lower cell may be an appropriate description of past circulations, but not of the present one. Theories of the meridional overturning circulation have largely focused on the zonally averaged perspective and ignored zonal interbasin exchanges. Only recently Jones and Cessi (2016) and Thompson et al. (2016) have extended those theories to study the impact of interbasin exchanges on the ocean stratification and water mass transformations. Here we build on these previous works to investigate the key differences between the overturning in the Atlantic and Indo-Pacific basins. First we introduce a simple dynamical model of the meridional overturning circulation based on the Ph.D. work of Allison (2009). The model consists of two closed basins connected through a reentrant channel to the south to mimic the Atlantic Ocean, the Indo-Pacific Ocean, and the Southern Ocean. The model is used to illustrate the overturning circulation that develops in three limits: 1) no diapycnal mixing in the ocean interior, 2) no convection in the North Atlantic, and 3) perfect compensation between eddy and wind-driven transports in the Southern Ocean. These three limits are then illustrated with full three-dimensional simulations of the ocean circulation. Finally we use these limits to 


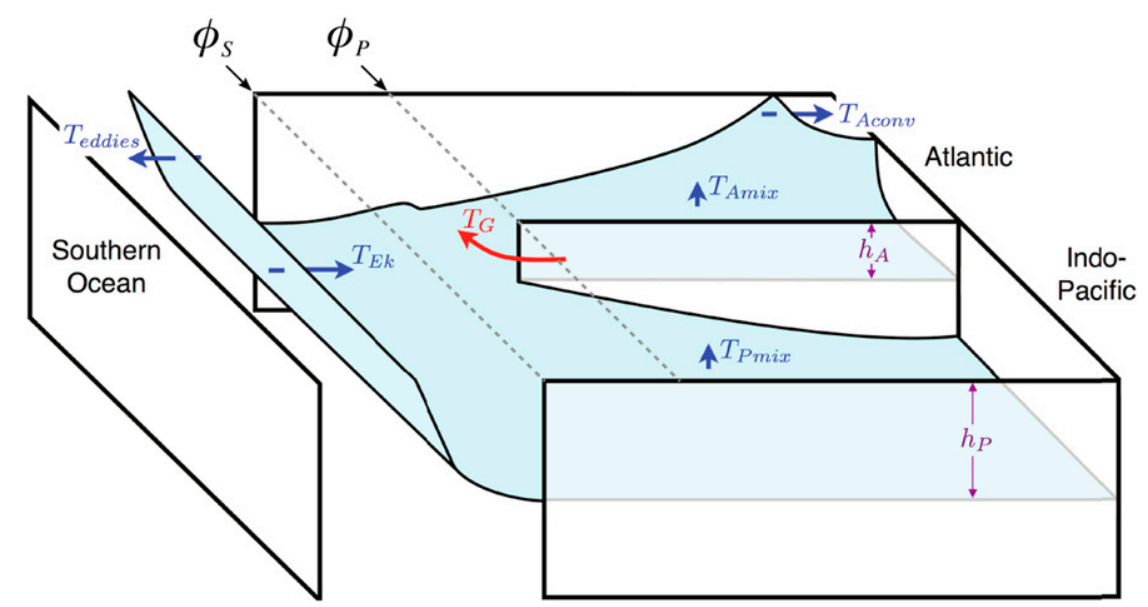

FIG. 2. Theoretical model configuration. Two ocean basins separated by two strips of land, extending to latitudes $\phi_{P}$ and $\phi_{S}$, are connected to a reentrant channel to the south. The model consists of two layers separated by an isopycnal (blue surface). The interface depth is nearly uniform in the basins, except along the narrow western boundary currents, while it comes to the surface in the channel. The interface depth along the eastern boundary of the narrow Atlantic basin, $h_{A}$, is shallower than along the eastern boundary of the wide Indo-Pacific basin, $h_{P}$. This difference drives an adiabatic (i.e., not crossing the interface) geostrophic flow, $T_{G}$, out of the Indo-Pacific basin above the interface and in the reverse direction below the interface. Five processes drive flows across the interface: mixing drives upwelling in the basins $\left(T_{\mathrm{Amix}}\right.$ in the Atlantic basin and $T_{\text {Pmix }}$ in the Indo-Pacific basin), convection drives downwelling in the North Atlantic basin $\left(T_{\text {Aconv }}\right)$, winds and eddies drives diabatic horizontal flows at the surface across the circumpolar current in the channel ( $T_{\mathrm{Ek}}$ and $T_{\text {eddies }}$, respectively).

gain insight into the observed ocean overturning circulation.

This paper is organized as follows. We introduce the theoretical model of the meridional overturning circulation in section 2, and we derive scalings for the overturning in the Atlantic and Indo-Pacific basins in three salient limits in section 3 . In section 4, we describe a three-dimensional general circulation model of the ocean circulation used to test the predictions of the theoretical model and connect our results to the full three-dimensional ocean overturning circulation in section 5. Finally, in section 6, we offer our conclusions.

\section{Theoretical model setup}

Gnanadesikan (1999) proposed a simple model of the deep stratification and overturning circulation of the Atlantic Ocean. Despite its simplicity, the model has proven very useful to interpret results from full threedimensional simulations of the global ocean circulation (e.g., Allison et al. 2011; Munday et al. 2011). Our goal is to extend Gnanadesikan's framework to an ocean with two basins connected at the south through a reentrant channel. We follow the approach outlined by Allison in her Ph.D. thesis (Allison 2009), recently used by Jones and Cessi (2016) to study the asymmetries in stratification between the Atlantic and Indo-Pacific Oceans and by Thompson et al. (2016) to study global water mass transformations.

The model geometry is illustrated in Fig. 2. A zonally reentrant channel, which represents the Southern Ocean, is connected at its northern edge to two basins, representing the Atlantic and Indo-Pacific Oceans. The basins are separated by two narrow strips of land of different meridional extent, reflecting the latitudinal difference between the southern limits of South America and South Africa. The two basins have different areas roughly corresponding to those of the Atlantic and Indo-Pacific Oceans. Values for the model parameters are given in Table 1. Although the geometry of the domain is highly idealized, for discussion purposes the two basins shall be referred to as the Atlantic and IndoPacific basins (the Atlantic being the smaller basin). The zonally unbounded latitudes will be referred to as the channel, and the region to the north of the channel and south of the model's South Africa will be referred to as the southern strip.

In the vertical the model consists of two active layers of constant density separated by an interface. The same two-layer, two-basin model was considered by Veronis $(1973,1976,1978)$ in his seminal studies of wind and 
TABLE 1. Representative values of the parameters used in the theoretical model.

\begin{tabular}{lcc}
\hline \hline \multicolumn{1}{c}{ Variable } & Value & Units \\
\hline$\tau$ & 0.16 & $\mathrm{~N} \mathrm{~m}^{-2}$ \\
$\kappa_{\mathrm{GM}}$ & 1000 & $\mathrm{~m}^{2} \mathrm{~s}^{-1}$ \\
$\kappa_{V}$ & $10^{-4}$ & $\mathrm{~m}^{2} \mathrm{~s}^{-1}$ \\
$\rho_{0}$ & 1000 & $\mathrm{~kg} \mathrm{~m}^{-3}$ \\
$\Delta b$ & 0.02 & $\mathrm{~m} \mathrm{~s}^{-2}$ \\
$A_{P}$ & $2.1 \times 10^{14}$ & $\mathrm{~m}^{2}$ \\
$A_{A}$ & $1.1 \times 10^{14}$ & $\mathrm{~m}^{2}$ \\
$A_{S}$ & $0.7 \times 10^{14}$ & $\mathrm{~m}^{2}$ \\
$f_{P}\left(30^{\circ} S\right)$ & $-7.3 \times 10^{-5}$ & $\mathrm{~s}^{-1}$ \\
$f_{S}\left(46^{\circ} \mathrm{S}\right)$ & $-1.1 \times 10^{-4}$ & $\mathrm{~s}^{-1}$ \\
$f_{N}\left(65^{\circ} \mathrm{N}\right)$ & $1.3 \times 10^{-4}$ & $\mathrm{~s}^{-1}$ \\
$L_{x}\left(180^{\circ}\right)$ & $10^{4}$ & $\mathrm{~km}$ \\
$\ell\left(74^{\circ}-55^{\circ} \mathrm{S}\right)$ & 2000 & $\mathrm{~km}$ \\
\hline
\end{tabular}

thermally driven circulations. In today's ocean, the lower layer is meant to represent dense waters formed at high latitudes, NADW and AABW. The upper layer instead includes the lighter waters sitting above these dense waters: thermocline, intermediate, and Indian and Pacific Deep Waters. In today's Atlantic Ocean the interface would thus correspond to the neutral density surface $27.8 \mathrm{~kg} \mathrm{~m}^{-3}$, which separates NADW and intermediate waters, while in today's Indo-Pacific Ocean it would correspond to the neutral density surface $28.0 \mathrm{~kg} \mathrm{~m}^{-3}$, which separates AABW and Indian and Pacific Deep Waters (Lumpkin and Speer 2007). Based on this configuration, scalings can now be derived for the water mass fluxes across the interface in each basin, following the approach of Gnanadesikan (1999), but with the all-important physics of zonal interbasin exchange.

The volume budget for the upper layer of each basin is the result of all the processes that exchange mass with the lower layer and with the southern strip to the south. The flow out of each basin toward the southern strip is geostrophic and can thus be estimated from the zonal pressure gradients across the basin. These pressure gradients have a simple expression for the particular geometry of the problem we are considering. A meridional pressure gradient cannot be sustained along an eastern boundary, since the Coriolis force necessary to balance it would require a flow through the coastline (e.g., Luyten et al. 1983; Marotzke 1997). For this reason, the interface depth along the eastern boundary of each basin can be assumed constant, at least on time scales longer than the transit time of a coastal Kelvin wave. Since the Kelvin waves that propagate southward with the coast on their left can travel around the southern tip of the landmass, the interface depth in the south west corner of each basin is equal to this uniform eastern boundary value in the basin to the west. ${ }^{1}$

Winds can drive an Ekman flow in and out of each basin, in addition to the geostrophic one. However, the wind stress is close to its minimum at the latitude of the model's South Africa, where the easterlies turn into westerlies. Consistently we will ignore the Ekman transport at the southern edge of the two basins, but the model could be easily extended to include it.

First we consider the geostrophic transport out of the Indo-Pacific basin. This geostrophic transport, marked as $T_{G}$ in Fig. 2, arises from the difference in layer thickness at either side of the southern boundary of the Indo-Pacific at the latitude of the model's South Africa $\phi_{P}$, that is, the difference between the eastern boundary interface depths in the two basins ${ }^{2}$ (Veronis 1973; Johnson and Marshall 2004). Direct estimates show that velocities in the Southern Ocean are much larger in the upper kilometer, a depth shallower than the interface of our two-layer model. Consistently we assume that velocities in the lower layer can be neglected and impose that the geostrophic flow is confined to the upper layer as done in reduced gravity models of the ocean circulation. The upper-layer geostrophic transport is thus equal to

$$
T_{G} \equiv-\frac{\Delta b}{2\left|f_{P}\right|}\left(h_{P}^{2}-h_{A}^{2}\right),
$$

where $\Delta b$ is the buoyancy difference between the two layers; $f_{P}$ is the Coriolis frequency at the latitude $\phi_{P}$; and $h_{P}$ and $h_{A}$ are the depths of the interface along the

\footnotetext{
${ }^{1}$ Cessi and Wolfe (2009) pointed out that eddy fluctuations can support meridional density gradients along eastern boundaries, but these effects appear to be small on the large scale as can be verified from any hydrographic atlas. Jones and Cessi (2016), for example, show the depth of three middepth neutral density surfaces as a function of latitude at three longitudes corresponding to the Atlantic $\left(30^{\circ} \mathrm{W}\right)$, Indian $\left(90^{\circ} \mathrm{E}\right)$, and Pacific $\left(150^{\circ} \mathrm{W}\right)$ Oceans. The surfaces are quite flat everywhere except at high latitudes, where convection drives strong vertical motions. While their sections are not right on the eastern boundaries, similar patterns are found along the eastern boundaries.

${ }^{2}$ The geostrophic transport $T_{G}$ out of the Indo-Pacific at the latitude $\phi_{P}$ remains proportional to the difference between the eastern boundary interface depths in the two basins even if the continent has a finite width. Consider a rectangular continent. The interface cannot change depth along the southern edge of the continent, because any change would drive a geostrophic flow into the continent. However, this is no longer true if the southern edge of the continent is not zonal and/or supports a nongeostrophic boundary current. While such corrections may be important to properly quantify the transport around the tip of South Africa, they are of secondary importance in this study, where we ignore all details about realistic continental configurations.
} 
eastern boundaries of the Indo-Pacific and Atlantic basins, respectively.

The geostrophic transport at the southern edge of the Atlantic basin, at latitude $\phi_{P}$, is not equal and opposite to $T_{G}$, because the presence of western boundary currents results in departures of the interface depth from $h_{P}$ at that latitude. The interface depth is equal to $h_{P}$ only at the southern edge of the western boundary, where the continental barrier meets the channel, but not north of it, at latitude $\phi_{P}$.

In steady state the geostrophic transport out of the Indo-Pacific basin is balanced by basinwide upwelling associated with diapycnal mixing, $T_{\mathrm{Pmix}}$, since there is no deep convection in the Indo-Pacific to release water from the upper layer. This diabatic transport is parameterized based on a simple advective-diffusive balance, in which the upward advective flux of dense water is balanced by a downward diffusive flux of density driven by turbulent diapycnal mixing (Munk 1966), $w^{*} \rho_{z} \approx \kappa_{V} \rho_{z z}$, where $w^{*}$ is a diapycnal velocity and $\kappa_{V}$ is the diapycnal diffusivity. At the scaling level, the advective-diffusive balance implies that $w^{*} \sim \kappa_{V} / h_{P}$ and thus the diabatic transport integrated over the whole Indo-Pacific interfacial area $A_{P}$ is

$$
T_{\text {Pmix }} \equiv \frac{\kappa_{V} A_{P}}{h_{P}} .
$$

This scaling assumes that the interface depth in the Indo-Pacific basin is approximately constant and equal to $h_{P}$, its value on the eastern boundary, a reasonable overall assumption, except along the narrow western boundary currents and in regions of strong upwelling/ downwelling where the interface suddenly steepens (Allison et al. 2011). A similar scaling holds for diapycnal mixing across the interface in the Atlantic basin:

$$
T_{\text {Amix }} \equiv \frac{\kappa_{V} A_{A}}{h_{A}} .
$$

The Southern Hemisphere westerlies drive a surface Ekman transport out of the channel toward the basins. The Ekman transport across the northern boundary of the channel at latitude $\phi_{S}$ is equal to

$$
T_{\mathrm{Ek}} \equiv \frac{\tau_{S}}{\rho_{0}\left|f_{S}\right|} L_{x},
$$

where $\tau_{S}$ is the average wind stress blowing along the northern edge of the channel at latitude $\phi_{S}$; and $f_{S}$ and $L_{x}$ are the Coriolis frequency and the circumpolar length, respectively, at that latitude. To be more precise, the transport should be computed along a mean barotropic streamline following the meanders of the circumpolar current (Allison et al. 2010), but at the scaling level the barotropic streamline can be approximated by a circumpolar line.

The equatorward Ekman transport across the latitude $\phi_{S}$ is opposed by a poleward eddy transport induced by the baroclinic instability of the circumpolar current. The eddy transport is the result of correlations between velocity and layer thickness fluctuations, which act to release the available potential energy by flattening density surfaces. Gent and McWilliams (1990) argued that this transport can be represented as a downgradient flux of isopycnal thickness, with diffusivity coefficient $\kappa_{\mathrm{GM}}$ :

$$
T_{\text {eddies }}=-\kappa_{\mathrm{GM}} \frac{\partial h}{\partial y} .
$$

If the interface comes to the surface a distance $\ell$ south of the latitude $\phi_{S}$, the thickness slope can be approximated as the ratio of the layer thickness at the northern edge of the channel, $h_{P}$, and the meridional distance $\ell$. The zonally integrated poleward eddy transport can therefore be approximated by

$$
T_{\text {eddies }} \equiv-\kappa_{\mathrm{GM}} \frac{h_{P}}{\ell} L_{x} .
$$

In the present-day ocean the density surfaces that separate intermediate from deep waters and deep to abyssal waters both outcrop close to Antarctica and therefore $\ell$ will be taken as the whole $20^{\circ}$ width of the Southern Ocean or approximately $2000 \mathrm{~km}$.

The sum of the Ekman and eddy transports is directed along density surfaces in the ocean interior, but it crosses isopycnals in the surface mixed layer (i.e., isopycnals become vertical as a result of surface mixing while the transports remain horizontal). This surface crossisopycnal flow represents the transport across the interface in the two-layer model.

Finally, in the present-day climate air-sea surface fluxes drive deep convection in the North Atlantic, but not in the North Pacific (Warren 1983; Weaver et al. 1999). Deep convection converts light waters from the upper layer into denser waters that sink into the lower layer. Scaling laws for this convective transport are not as well established as those for the other processes considered so far. The scaling proposed by Gnanadesikan (1999) assumes a balance between meridional pressure gradients and friction within the western boundary current. The same scaling has been derived by Nikurashin and Vallis (2012) assuming that the convective sinking equals the eastward geostrophic transport that develops when the upper layer outcrops at the ocean surface in the high northern latitudes. 
In either case, $T_{\text {Aconv }}$ is proportional to $h_{A}^{2}$ and has the following form:

$$
T_{\text {Aconv }} \equiv \frac{1}{2} \frac{\Delta b h_{A}^{2}}{\left|f_{N}\right|},
$$

where $f_{N}$ is the latitude where convection occurs in the North Atlantic basin. In the analysis to follow we will assume that the convective transport is prescribed to avoid committing to a particular scaling law. But, for completeness, we will also discuss the implications of having a transport $T_{\text {Aconv }}$ proportional to $h_{A}^{2}$.

This model represents a minimal extension of the approach pioneered by Gnanadesikan (1999) to study the ocean overturning circulation, which considered a single basin exchanging waters with a reentrant channel. The addition of a second basin allows for different overturning circulation patterns in the two basins, which we show are key to interpreting the complex overturning circulation pathways observed in the ocean (e.g., Schmitz 1995; Lumpkin and Speer 2007; Talley 2013). Thompson et al. (2016) used a multilayer version of this model to study the conversions between abyssal, deep, and intermediate water masses in the global ocean. Here we sacrifice realism to obtain a model where we can make analytical progress and derive scaling laws that connect the interbasin exchanges with the overturning circulation in the two basins. In section 3 we will identify three limit overturning circulations captured by the model and in section 5 we will use these limit circulations to interpret the overturning circulation in a fully threedimensional model with a circulation qualitatively consistent with that observed in the ocean.

\section{Overturning circulations predicted by the theoretical model}

The scaling laws for the various transports can be combined to write down the volume budgets of the upper layer; the lower layer transports must be equal and opposite to conserve mass. Starting with the Indo-Pacific basin we have a balance between the diapycnal mixingdriven upwelling and the geostrophic flow as sketched in Fig. 2:

$$
-\frac{\Delta b}{2\left|f_{P}\right|}\left(h_{P}^{2}-h_{A}^{2}\right)+\frac{\kappa_{V} A_{P}}{h_{P}}=0 .
$$

The geostrophic transport $-\Delta b\left(h_{P}^{2}-h_{A}^{2}\right) / 2\left|f_{P}\right|$ must be negative, indicating a southward flow out of the IndoPacific basin, to balance the upwelling. For this to be the case, the interface must be deeper in the Indo-Pacific than it is in the Atlantic. Jones and Cessi (2016) show compelling evidence from hydrography that middepth density surfaces are indeed shallower in the Atlantic than in the Pacific Ocean. The difference in depth is of the order of $100 \mathrm{~m}$, giving a net geostrophic transport of $O$ (10) $\mathrm{Sv}\left(1 \mathrm{~Sv} \equiv 10^{6} \mathrm{~m}^{3} \mathrm{~s}^{-1}\right)$ for interface depths in the range of 1000-2000 $\mathrm{m}$ and using Eq. (1) together with the parameters given in Table 1 . Thus, $\left|h_{P}-h_{A}\right| \ll h_{P} \simeq h_{A}$, otherwise the geostrophic transport, and the diabatic upwelling in the Indo-Pacific, becomes unrealistically large. Under this approximation the budget for the IndoPacific basin in Eq. (8) reduces to

$$
-\frac{\Delta b}{\left|f_{P}\right|} h_{P} \delta h+\frac{\kappa_{V} A_{P}}{h_{P}} \simeq 0,
$$

where $\delta h \equiv h_{P}-h_{A}$.

The volume budget for the upper layer in the L-shaped region covering the Atlantic basin and the southern strip between the model's South Africa and South America, is given by

$$
\begin{gathered}
\frac{\tau_{S}}{\rho_{0}\left|f_{S}\right|} L_{x}-\kappa_{\mathrm{GM}} \frac{h_{P}}{\ell} L_{x}+\frac{\Delta b}{\left|f_{P}\right|} h_{P} \delta h \\
+\frac{\kappa_{V} A_{S}}{h_{P}}+\frac{\kappa_{V} A_{A}}{h_{P}}-T_{\text {Aconv }} \simeq 0
\end{gathered}
$$

where $A_{A}$ is the area of the Atlantic basin and $A_{S}$ is the area of the southern strip. For analytical convenience we use the same interface depth $h_{P}$ in the denominator of all diapycnal mixing-driven transports, consistent with the assumption that variations in interface depth among the various regions are small compared to the mean interface depth.

Substituting the expression for the geostrophic transport from the Indo-Pacific basin budget [Eq. (9)] in the budget for the L-shaped region [Eq. (10)], we find,

$$
\frac{\tau_{S}}{\rho_{0}\left|f_{S}\right|} L_{x}-\kappa_{\mathrm{GM}} \frac{h_{P}}{\ell} L_{x}+\frac{\kappa_{V} A_{\mathrm{tot}}}{h_{P}}-T_{\mathrm{Aconv}} \simeq 0,
$$

where $A_{\text {tot }}=A_{P}+A_{A}+A_{S}$ is the total area enclosed by lateral continents. This scaling is a generalization of the global buoyancy budget first presented by Munk (1966) in his seminal paper on abyssal recipes. Deep waters formed at high latitudes are transformed back into lighter waters by diapycnal mixing. There is, however, an important difference from Munk's original argument. Only in the North Atlantic basin does convection always transform intermediate water back to deep water. In the channel winds bring deep water to the surface to be transformed into lighter water, while geostrophic eddies drive an opposite transformation. If the eddy transport dominates, then the channel creates deep water like the North Atlantic basin and the transformation back 
to intermediate is achieved exclusively by diapycnal mixing in the basins, as in Munk's view. If the Ekman transport is dominant, the channel acts together with diapycnal mixing to transform the deep water formed in the North Atlantic basin back to intermediate water. Despite the similarity to Munk's view, one should not forget that in our model there is an important exchange of waters between basins given in Eq. (9) that is hidden in the global average.

In the next three sections, we consider three distinguished limits of the circulations emerging from Eqs. (9) and (10). These limits will help to illustrate the key importance of interbasin exchanges in achieving an adiabatic circulation in the Atlantic basin and a diabatic circulation in the Indo-Pacific basin. Furthermore we will show that the compensation between the Ekman and eddy-driven circulations observed in the Southern Ocean (Marshall and Speer 2012) demands a strong geostrophic exchange of waters between the Atlantic and Indo-Pacific Oceans as described by Talley (2013) from hydrographic observations.

\section{a. Adiabatic overturning: Limit of no diapycnal mixing}

In the limit of no diapycnal mixing $\left(\kappa_{V}=0\right)$, there can be no overturning in the Indo-Pacific basin. In turn this requires that there be no geostrophic transport entering into the Indo-Pacific basin and Eq. (10) reduces to

$$
\frac{\tau_{S}}{\rho_{0}\left|f_{S}\right|} L_{x}-\kappa_{\mathrm{GM}} \frac{h_{A}}{\ell} L_{x}-T_{\mathrm{Aconv}} \simeq 0, \quad \delta h \simeq 0,
$$

where we substituted $h_{A}$ for $h_{P}$, since they are equal in this limit. The overturning is confined to the Atlantic basin and the channel. Water sinks through convection in the north, flows adiabatically to the channel, where it upwells and is converted back into intermediate water through surface warming and precipitation. The flow in the upper layer is sketched in Fig. 3a; the flow in the lower layer is equal and opposite as dictated by mass conservation. This is the Gnanadesikan (1999) model in the limit of no diapycnal mixing. (The full Gnanadesikan model is recovered by retaining diapycnal mixing in the Atlantic basin only.)

The distance $\ell$ between the northern edge of the channel and the latitude at which the interface comes to the surface is set through the surface boundary condition. For a restoring boundary condition (Haney 1971), $\ell$ is set by the atmospheric temperature profile, if temperature dominates the density field. This is typically the case for the interface that separates deep and intermediate waters. The only unknown parameter is therefore the interface depth, which can be obtained from Eq. (12):

$$
h_{A} \simeq h_{P} \simeq \frac{\tau_{S} \ell}{\rho_{0}\left|f_{S}\right| \kappa_{\mathrm{GM}}}\left(1-\frac{T_{\mathrm{Aconv}}}{\tau_{S} L_{x} / \rho_{0}\left|f_{S}\right|}\right) .
$$

The interface depth is the same in the two basins and it is positive definite, because the convective transport, $T_{\text {Aconv }}$, cannot be larger than the Ekman transport in the channel, $\tau_{S} L_{x} / \rho_{0}\left|f_{S}\right|$. In the absence of diapycnal mixing, waters sinking into the lower layer in the North Atlantic basin can only be brought back to the upper layer by Ekman-driven upwelling in the channel. The strength of the overturning is set by the prescribed convective transport $T_{\text {Aconv }}$. In the limit of strong convection, the interface is shallow and eddy transports, which are proportional to the interface depth, are small. In the limit of weak convection, the interface deepens and the overturning shuts off; in the channel this is achieved by a near-perfect compensation between the Ekman and eddy-driven transports.

This adiabatic limit shows that an overturning circulation can be generated even without any diapycnal mixing, but such a circulation is confined to the Atlantic basin while the Indo-Pacific basin is stagnant. This limit has been used to describe the adiabatic overturning in the Atlantic Ocean (e.g., Wolfe and Cessi 2011; Munday et al. 2011). However the analogy should not be carried too far, because, in reality, only a small fraction of the NADW formed though convection in the North Atlantic is transformed back into lighter intermediate water once it upwells in the Southern Ocean, as demanded by the model, while a larger fraction is transformed into even denser AABW and flows to the bottom of the Indo-Pacific and Atlantic Oceans (Schmitz 1995; Lumpkin and Speer 2007; Talley 2013).

\section{b. Diabatic overturning: Limit of no convection in the Atlantic basin}

This is the limit of a purely diabatic circulation considered by Welander (1986), Johnson et al. (2007), and Nikurashin and Vallis (2011) (i.e., a circulation where diapycnal mixing dominates in all basins). In this limit Eq. (10) reduces to

$$
\frac{\tau_{S}}{\rho_{0}\left|f_{S}\right|} L_{x}-\kappa_{\mathrm{GM}} \frac{h_{P}}{\ell} L_{x}+\frac{\kappa_{V} A_{\mathrm{tot}}}{h_{P}} \simeq 0 .
$$

The main difference with the model of Nikurashin and Vallis (2011) is that there is an interbasin exchange given by Eq. (9). The circulation is sketched in Fig. 3b: deep water is transformed into intermediate water through mixing in both basins, while the opposite transformation is achieved in the channel. Water above the interface flows from the basins to the channel.

If diapycnal mixing is weak (i.e., the diabatic overturning in the basins is much smaller than the overturning 
(a)

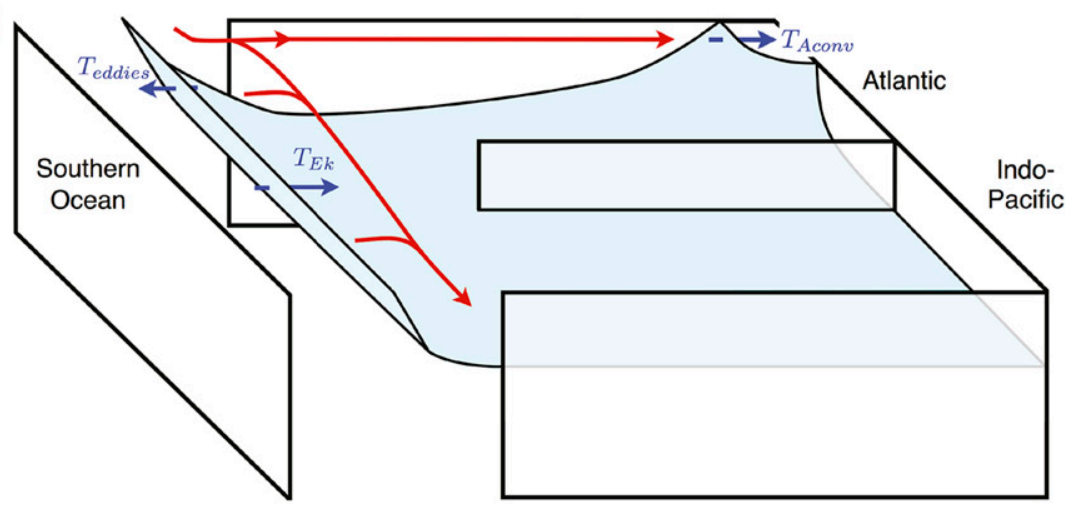

(b)

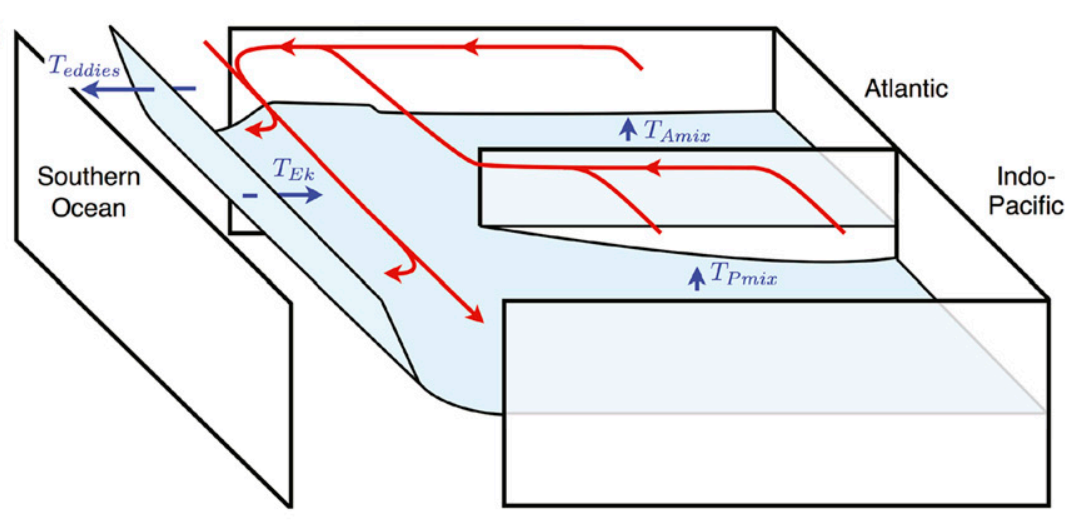

(c)

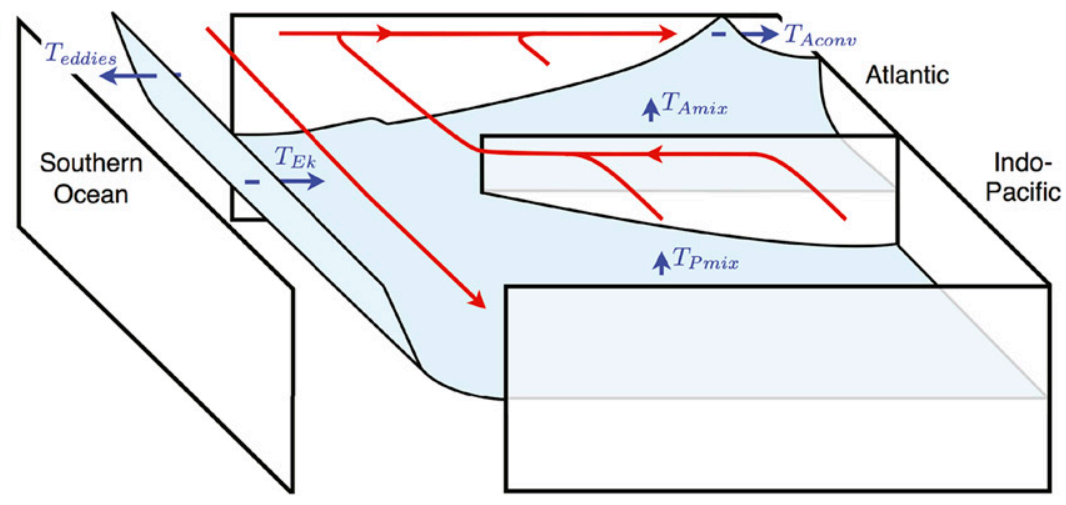

FIG. 3. Schematic representation of the upper layer adiabatic flows (red arrow) and the diabatic flows across the interface (blue arrows) implied by the theoretical model setup shown in Fig. 2 for the three limits identified in section 3. The adiabatic flow in the lower layer is equal and opposite to that in the upper layer as dictated by mass conservation in each basin. (a) The adiabatic overturning circulation in the limit of no mixing. (b) The diabatic overturning circulation in the limit of no convection in the North Atlantic basin. (c) The interbasin overturning circulation in the limit of no overturning in the southern channel due to a cancellation between Ekman and eddy flows, the so-called compensation limit. The adiabatic exchange of waters between the two basins requires a geostrophic flow that can be captured only with a two-basin model of the overturning. 
generated by winds in the channel), then there must be strong compensation between the Ekman and eddydriven circulations in the channel. The compensation requires that at leading order,

$$
h_{P} \simeq \frac{\tau_{S} \ell}{\rho_{0}\left|f_{S}\right| \kappa_{\mathrm{GM}}}, \quad \delta h \simeq 0 .
$$

This depth is larger than in the adiabatic limit. Both the interbasin exchange and the overturning are proportional to the weak diapycnal diffusivity $\kappa_{V}$ and thus weak. While wind-eddy compensation is observed in the Southern Ocean (Marshall and Speer 2012), diapycnal mixing drives a strong diabatic upwelling, at least in the Indo-Pacific basin (Lumpkin and Speer 2007). Thus, this limit does not capture the basic balance observed in the present-day Indian and Pacific Oceans.

If diapycnal mixing is strong and drives an overturning larger than the wind-driven Ekman transport in the channel, then the eddy transport balances mixing:

$$
h_{P} \simeq \sqrt{\frac{\kappa_{V}}{\kappa_{\mathrm{GM}}} \frac{\ell}{L_{X}} A_{\mathrm{tot}}}, \quad \delta h \simeq \frac{\left|f_{S}\right|}{\Delta b} \frac{L_{x}}{\ell} \frac{A_{P}}{A_{\mathrm{tot}}} \kappa_{\mathrm{GM}},
$$

and

$$
T_{G} \simeq-\sqrt{\kappa_{V} \kappa_{\mathrm{GM}} \frac{L_{x}}{\ell} \frac{A_{P}^{2}}{A_{\mathrm{tot}}}} .
$$

These scalings give a sizable overturning driven by a combination of diabatic processes in the basins and eddies in the channel. Such a circulation is observed in the Indo-Pacific Ocean and in the deep Atlantic Ocean below the adiabatic overturning cell. This limit is therefore appropriate to describe the conversion of AABW to deep waters in the Atlantic and Indo-Pacific Ocean and the interface $h_{P}$ must be interpreted as the separation between abyssal and deep waters (rather than deep and intermediate waters.) Consistently this interface sits below $2000 \mathrm{~m}$ in the real ocean, where diapycnal mixing is indeed large. This solution is, however, incomplete as it fails to capture the adiabatic overturning observed in the Atlantic Ocean, as pointed out in Nikurashin and Vallis (2012).

Figure $3 \mathrm{~b}$ shows that the upper layer water leaves the Indo-Pacific basin along a western boundary current and flow westward into the Atlantic basin. This is the warm route pathway, described by Rintoul (1991) and Gordon et al. (1992), which arises if the tip of "South Africa" lies in the latitude band of the subtropical gyres. At these latitudes the wind-driven circulation in the upper layer is anticyclonic and the waters flowing westward in the IndoPacific basin turn southward along the western boundary of the basin and then westward across the southern entrance of the Atlantic basin. This is best illustrated in Fig. 4c, which shows the barotropic streamfunction from a three-dimensional model configured with the same twobasin geometry used for the theoretical model and forced with realistic wind patterns (see section 4). This is the configuration we will consider in the rest of the paper. However, should the tip of South Africa be moved farther south to lie in the latitude band of the subpolar gyre, then the upper layer flow would reverse and go from the Atlantic to the Indo-Pacific following the cold route (Rintoul 1991; Gordon et al. 1992). From the perspective of the overturning circulation pattern, it makes little difference which route the waters take, but it has important implications for the exchange of salinity between the two basins (Cessi and Jones 2017).

\section{c. Interbasin overturning: Limit of compensated Ekman and eddy transports in the channel}

A third circulation can arise with the two-basin model in the limit where Ekman and eddy transports in the channel balance. The two terms are almost an order of magnitude larger than all other terms in Eq. (11) and a first-order compensation therefore is expected (Marshall and Speer 2012). But it is useful to consider the circulation that arises in the limit when the Ekman and eddy transports perfectly balance, the so-called compensation limit. In this limit Eq. (9) and Eq. (10) reduce to

$$
\begin{aligned}
- & \frac{\Delta b}{\left|f_{P}\right|} h_{P} \delta h+\frac{\kappa_{V} A_{P}}{h_{P}} \simeq 0, \\
& \frac{\Delta b}{\left|f_{P}\right|} h_{P} \delta h+\frac{\kappa_{V}\left(A_{A}+A_{S}\right)}{h_{P}}-T_{\text {Aconv }} \simeq 0 .
\end{aligned}
$$

The first equation states that the diabatic upwelling of deep Indo-Pacific water feeds a geostrophic transport of intermediate water from the Indo-Pacific to the Atlantic basin in the upper layer. The second equation shows that diabatic upwelling of deep water in the southern strip and the Atlantic basin further increases the volume of upper layer intermediate water that eventually sinks through convection in the north. Summing the two equations, one gets a balance between deep water formed through convection in the North Atlantic and diapycnal mixing-driven upwelling. This limit is reminiscent of Munk's argument (1966), except for the lack of deep water formation in the channel under the compensation assumption. In the absence of sinking of dense water in the channel, the lower layer is filled with the model's equivalent of NADW, while there is no equivalent of $\mathrm{AABW}$.

Compensation between Ekman and eddy transports requires that 

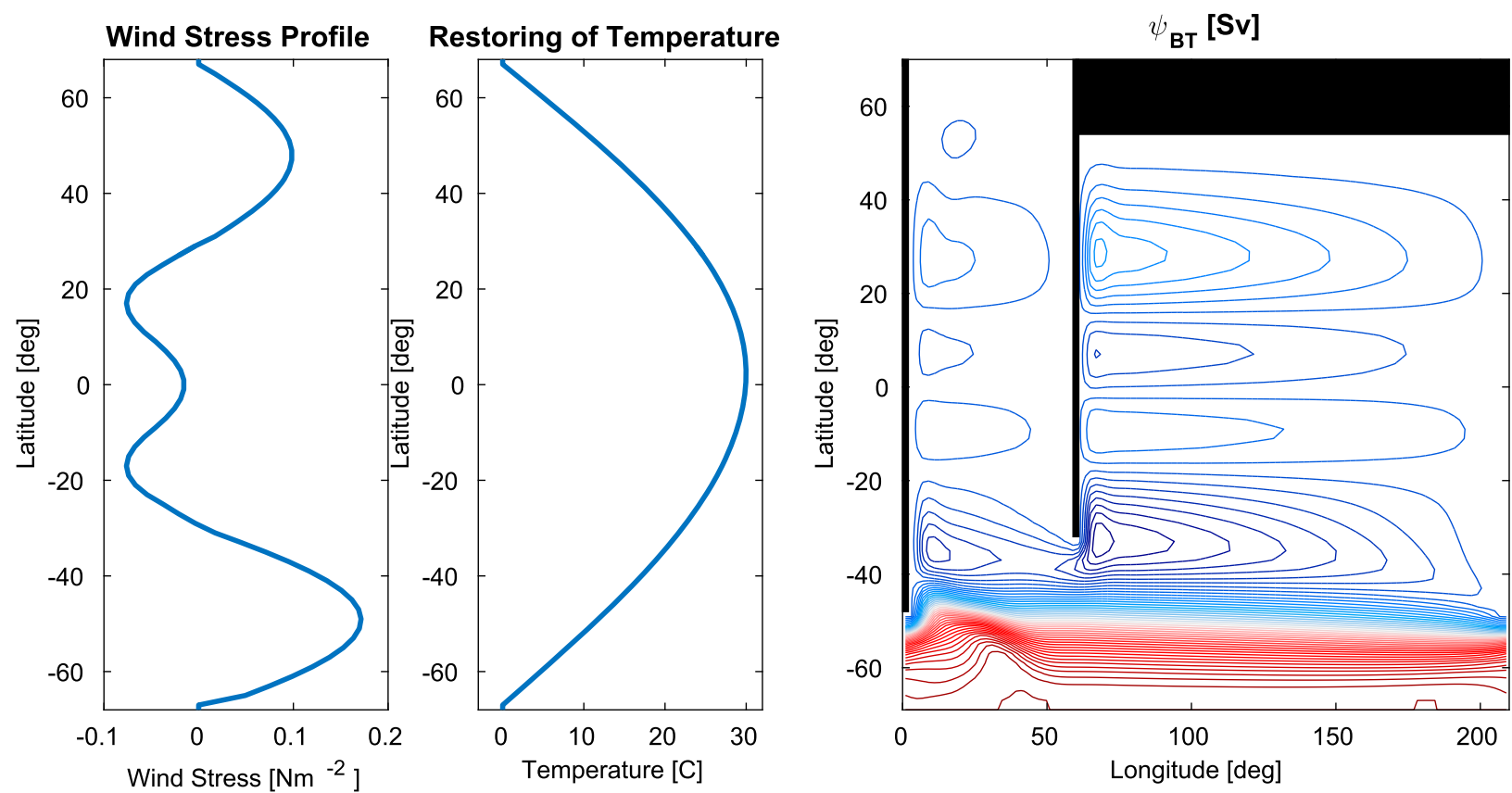

FIG. 4. Three-dimensional model configuration for the reference present-day-like experiment: (left) latitudinal profile of surface wind stress, (center) latitudinal profile of the restoring temperature, and (right) model geometry and the barotropic streamfunction for the reference present-day-like experiment. The streamlines are shown at intervals of $10 \mathrm{~Sv}$.

$$
\frac{\tau_{S}}{\rho_{0}\left|f_{S}\right|} L_{x}-\kappa_{\mathrm{GM}} \frac{h_{P}}{\ell} L_{x} \simeq 0 .
$$

This constraint is equivalent to a zero air-sea flux boundary condition over the channel: a nonzero surface flux would require a net transport across the interface representing the water density change in response to the flux. This limit is achieved by choosing the appropriate $\ell$ that satisfies Eq. (19).

This overturning circulation is depicted in Fig. 3c. Water sinks into the lower layer in the North Atlantic basin. The deep water then flows directly into the IndoPacific basin, through the southern strip between the model's South Africa and the channel, where it is transformed back into intermediate waters through mixing. There is no overturning circulation in the channel, because the Ekman and eddy transports cancel each other. This limit captures the observed asymmetry in overturning circulation in the Atlantic and IndoPacific Oceans. The Atlantic overturning circulation converts light water into dense in the north and it is mostly adiabatic elsewhere, except for some mixingdriven upwelling. The Indo-Pacific circulation flows in the opposite direction converting deep water into lighter water. The conversion is driven by mixing in the basin interior and it is purely diabatic. The model suggests that this asymmetry is connected to the exchange of waters between the two basins.
Talley (2013) infers from hydrographic observations that most of the NADW formed in the North Atlantic flows adiabatically to the Southern Ocean, where it is transformed into AABW, and then flows to the Pacific Ocean, where it upwells through diapycnal mixing. The interbasin overturning limit captures Talley's observation that a large fraction of the deep water formed in the North Atlantic end up in the Pacific rather than being returned back to the Atlantic as intermediate water (the pathway assumed in zonally averaged models and implied by the adiabatic limit). However this limit is an oversimplification of the true water mass transformations. By assuming a perfect compensation between Ekman and eddy transports, waters do not upwell in the Southern Ocean and there is not transformation of deep Atlantic water into abyssal IndoPacific water. This is not the case in the real ocean. The conversion of NADW into AABW and of Indian and Pacific Deep Waters into intermediate waters occurs as waters come to the surface in the Southern Ocean. It is because of these transformations that the Atlantic overturning is dominated by conversion of intermediate to deep water (NADW), while the Indo-Pacific one consists of abyssal water (AABW) converted into deep waters (Indian and Pacific Deep Waters). Thompson et al. (2016) derive a multiple layer model to capture all these conversions, but at the cost of much added complexity. Here we prefer to use the insights of the simpler 
two layer model and show how its predictions are useful in interpreting the overturning in more complex threedimensional models with full ocean physics. We return to this point in the conclusions, where we show how the three limit circulations can be used together to interpret the observed ocean overturning circulation.

The interbasin overturning limit has not been discussed in previous literature and it is therefore useful to investigate its predictions in more detail. In particular, it is useful to derive the scalings that emerge if one substitutes in Eqs. (18) the expression for the North Atlantic convection in Eq. (7). With this substitution, one obtains expressions for the interface depth and circulation strength that depend only on external parameters and can be tested with the simulations presented in the next section. Realizing that $h_{A}^{2} \simeq h_{P}^{2}-2 h_{P} \delta h$, under the assumption $\delta h \ll h_{P}$, one finds that the interface depth in the two basins scales as

$$
\begin{aligned}
& h_{p}=\left(\frac{A_{\mathrm{tot}}}{A_{P}}+\frac{\left|f_{P}\right|}{\left|f_{N}\right|}\right)^{1 / 3}\left(2 \frac{\left|f_{N}\right|}{\Delta b}\right)^{1 / 3}\left(A_{P} \kappa_{V}\right)^{1 / 3}, \\
& \delta h=\frac{\left|f_{P}\right|}{2\left|f_{N}\right|}\left(\frac{A_{\mathrm{tot}}}{A_{P}}+\frac{\left|f_{P}\right|}{\left|f_{N}\right|}\right)^{-1} h_{P},
\end{aligned}
$$

The $\kappa_{V}^{1 / 3}$ scaling for the depth of the interface is the same as that obtained by Gnanadesikan (1999) for a single basin in the limit of strong convection and diapycnal mixing. But our circulation is different, because it involves a strong interbasin circulation:

$$
T_{G}=-\left(\frac{A_{\mathrm{tot}}}{A_{P}}+\frac{\left|f_{P}\right|}{\left|f_{N}\right|}\right)^{-1 / 3}\left(\frac{2\left|f_{N}\right|}{\Delta b}\right)^{-1 / 3}\left(A_{P} \kappa_{V}\right)^{2 / 3} .
$$

The similarity in scaling arises because the Gnanadesikan model assumes that convection scales with $h_{A}^{2}$, the same quadratic dependence of the geostrophic transport on the interface depth. The dependence on the other parameters are, however, quite different.

\section{Numerical model}

The theoretical model of the overturning we have presented in the previous two sections is very crude and one may question its relevance to interpret the global ocean overturning circulation. To address this point we run a full three-dimensional ocean circulation model to illustrate how the different limits identified with the theoretical model arise in a more complex, and arguably more realistic, model.

The MITgcm ocean model (Marshall et al. 1997) is configured in the same idealized geometry assumed in the theoretical study. The domain consists of a spherical sector $210^{\circ}$ wide spanning the $70^{\circ} \mathrm{S}-70^{\circ} \mathrm{N}$ latitude range.
The ocean is $4000 \mathrm{~m}$ deep everywhere. A zonally reentrant channel occupies the area south of $46^{\circ} \mathrm{S}$, north of which are two rectangular basins. The basins are separated by two vertical sidewalls, one extending from $46^{\circ} \mathrm{S}$ to $70^{\circ} \mathrm{N}$ (representing the meridional extent of South America) and one extending from $30^{\circ} \mathrm{S}$ to $70^{\circ} \mathrm{N}$ (representing the meridional extent of South Africa). The narrower Atlantic-like basin is $60^{\circ}$ wide and the wider Indo-Pacific-like basin is $150^{\circ}$ wide. To create a buoyancy forcing asymmetry between the model's Atlantic and Indo-Pacific basins, a landmass is added between $54^{\circ}$ and $70^{\circ} \mathrm{N}$ in the northern Indo-Pacific basin. The areas of the two basins correspond approximately to those of the Atlantic and Indo-Pacific Oceans.

The model uses a $2^{\circ}$ horizontal grid. There are 40 vertical levels of thickness increasing from $37 \mathrm{~m}$ at the surface to $159 \mathrm{~m}$ at the bottom. The equation of state is linear and depends only on temperature, $\rho=\rho_{0}\left(1-\alpha_{\theta} \theta\right)$, with a constant thermal expansion coefficient $\alpha_{\theta}=2.0 \times$ $10^{-4} \mathrm{~K}^{-1}$. Hence, temperature is linearly related to density and can be used in place of density to describe the simulations. Baroclinic eddies are parameterized with the Gent and McWilliams (1990) closure scheme and a constant eddy diffusivity of $\kappa_{\mathrm{GM}}=1000 \mathrm{~m}^{2} \mathrm{~s}^{-1}$. Advection of temperature is by a second-order moment superbee flux limiter scheme (Roe 1985). Ocean convection is parameterized with convective adjustment, implemented as an enhanced vertical diffusivity of temperature.

Our reference setup is designed to depict the main features of the present-day ocean meridional overturning circulation and is shown in Fig. 4. Latitudinal profiles of zonal wind stress forcing and surface temperature restoring, broadly inspired by present-day observed fields, are shown in Figs. $4 \mathrm{a}$ and $4 \mathrm{~b}$, respectively. The wind stress is symmetric about the equator in the tropics and subtropics, but it is somewhat larger in the high-latitude Southern Hemisphere than in the high-latitude Northern Hemisphere, like in the present-day climate. The wind stress goes to zero at the latitude of the model's South Africa as assumed in the theoretical model, but the results below do not change appreciably if the zero wind stress latitude is moved $10^{\circ}$ to the south. The surface temperature is restored to a profile symmetric around the equator on a time scale of 30 days over the topmost grid cell of $37 \mathrm{~m}$. The model geometry and barotropic streamfunction for the reference setup are shown in Fig. 4c. To avoid an unrealistically large circumpolar barotropic transport, a $1500-\mathrm{m}$-high Gaussian ridge is added between the tip of the model's South America and the southern edge of the channel. The shape of the ridge follows an idealized Scotia Arc chosen to spread the topographic form drag over a larger area than a single grid point and generate a smoother standing meander of the 
circumpolar current. In the reference setup, a constant diapycnal diffusivity $\kappa_{V}=6 \times 10^{-5} \mathrm{~m}^{2} \mathrm{~s}^{-1}$ is used. Model diagnostics are computed over 500 years, after the model has reached statistical equilibrium.

\section{Numerical results}

We consider four model configurations. The first three configurations are meant to represent the three limits discussed in section 3 . The last reference configuration is meant to represent a present-day-like circulation.

\section{a. Adiabatic overturning simulation: Limit of weak diapycnal mixing}

First we consider a simulation in which the diapycnal diffusivity is set to a constant value $\kappa_{V}=1 \times 10^{-5} \mathrm{~m}^{2} \mathrm{~s}^{-1}$. Starting with Munk (1966), this value has been shown to be too weak to drive a substantial diabatic circulation. According to the scalings in section 3 , this simulation should be characterized by an adiabatic overturning circulation confined to the Atlantic basin.

The model meridional overturning circulation (MOC) is diagnosed from the simulation as the total mass transport within a temperature (density) layer:

$$
\begin{aligned}
& \psi_{\text {res }}(y, \theta) \\
& \quad=-\frac{1}{T} \int_{0}^{T} \int_{0}^{L_{x}} \int_{-H}^{-h(x, y, \theta, t)} v_{\text {res }}(x, y, z, t) d z d x d t,
\end{aligned}
$$

where $h(x, y, \theta, t)$ is the depth of the isotherm $\theta$ as a function of space and time, $H$ is the ocean depth, $L_{x}$ is the zonal extent over which the average is taken, and $T=$ $500 \mathrm{yr}$ is the period of the time average. The residual flow $v_{\text {res }}$ is given by the sum of the model velocity $v$ and the eddy-induced velocity $v_{\mathrm{GM}}$ parameterized with the Gent and McWilliams (1990) scheme. The function $\psi_{\text {res }}(y, \theta)$ is the most appropriate definition of the MOC as it represents the full transport by mean and eddy flows (Nurser and Lee 2004; Ferrari and Ferreira 2011).

In Fig. 5, the MOC streamfunction is plotted as a function of the zonal and temporal mean depth of each isotherm $z_{\theta}(y, \theta)=-\left(1 / T L_{x}\right) \int_{0}^{T} \int_{0}^{L_{x}} h(x, y, \theta, t) d x d t$. Zonal averages are computed for three different sectors of the model: (left) full domain, (center) narrow Atlantic basin, and (right) wide Indo-Pacific basin.

The global and basin MOCs for the simulation with weak mixing are shown in the upper row of Fig. 5. The MOCs are very consistent with the "adiabatic limit" described in section 3a. Below the wind-driven gyres that occupy the upper $500 \mathrm{~m}$, the MOC is confined to the narrow Atlantic basin, where surface cooling drives convection and sinking of waters down to $2000 \mathrm{~m}$ at its northern edge. These deep waters flow adiabatically, at constant temperature, between 1000 and $2000 \mathrm{~m}$, across the equator all the way to the channel, where Ekman-driven upwelling brings them back to the surface. The MOC in the wide Indo-Pacific-like basin is vanishingly small. This is the circulation described by Gnanadesikan (1999) and Wolfe and Cessi (2011), and it captures the adiabatic nature of the observed Atlantic Ocean MOC.

\section{b. Diabatic overturning simulation: Limit of no convection in the Atlantic-like basin}

The second row of Fig. 5 shows results for a simulation with no convection in the north of the narrow Atlantic basin and with moderate mixing. Convection is suppressed by imposing a no-flux surface condition north of $40^{\circ} \mathrm{N}$ in the Atlantic basin. The diapycnal diffusivity is set to $\kappa_{V}=6 \times 10^{-5} \mathrm{~m}^{2} \mathrm{~s}^{-1}$, which is 6 times larger than in the "adiabatic simulation." This setup should drive a circulation consistent with the diabatic limit described in section 3b. In both basins the MOC is characterized by diabatic counterclockwise abyssal cells. These cells are much deeper that in the adiabatic limit, consistent with the prediction of a deeper interface as per section $3 b$. The cells come to the surface in the channel, where waters are exposed to strong buoyancy loss, sink back to the ocean the bottom, fill basins, and rise diabatically crossing density surfaces thereby closing the overturning loop. The adiabatic clockwise middepth cell in the Atlantic basin is absent in this simulation. This limit is investigated in Johnson et al. (2007) and Nikurashin and Vallis (2011), and describes the basic features of the Indo-Pacific MOC, but not of the Atlantic one.

\section{c. Interbasin overturning simulation: Limit of compensated Ekman and eddy transports in the channel}

The third row of Fig. 5 shows results for a simulation where Ekman and eddy transports cancel each other in the southern channel to capture the limit discussed in section 3c. Ekman-eddy compensation is achieved by setting the surface buoyancy flux to zero south of $36^{\circ} \mathrm{S}$. As a result, the MOC vanishes in the latitude band of the reentrant channel.

In the narrow Atlantic basin, deep waters formed through convection in the north flow adiabatically toward the channel in the 2000-4000-m depth range. Once they reach the southern strip, the deep waters flow adiabatically from the bottom of the Atlantic basin to the bottom of the Indo-Pacific basin, where they upwell diabatically across density surfaces and return south toward the channel. The circulation is then closed by an adiabatic interbasin return flow in the upper $2000 \mathrm{~m}$ from the Indo-Pacific to the Atlantic basin, the 
Total
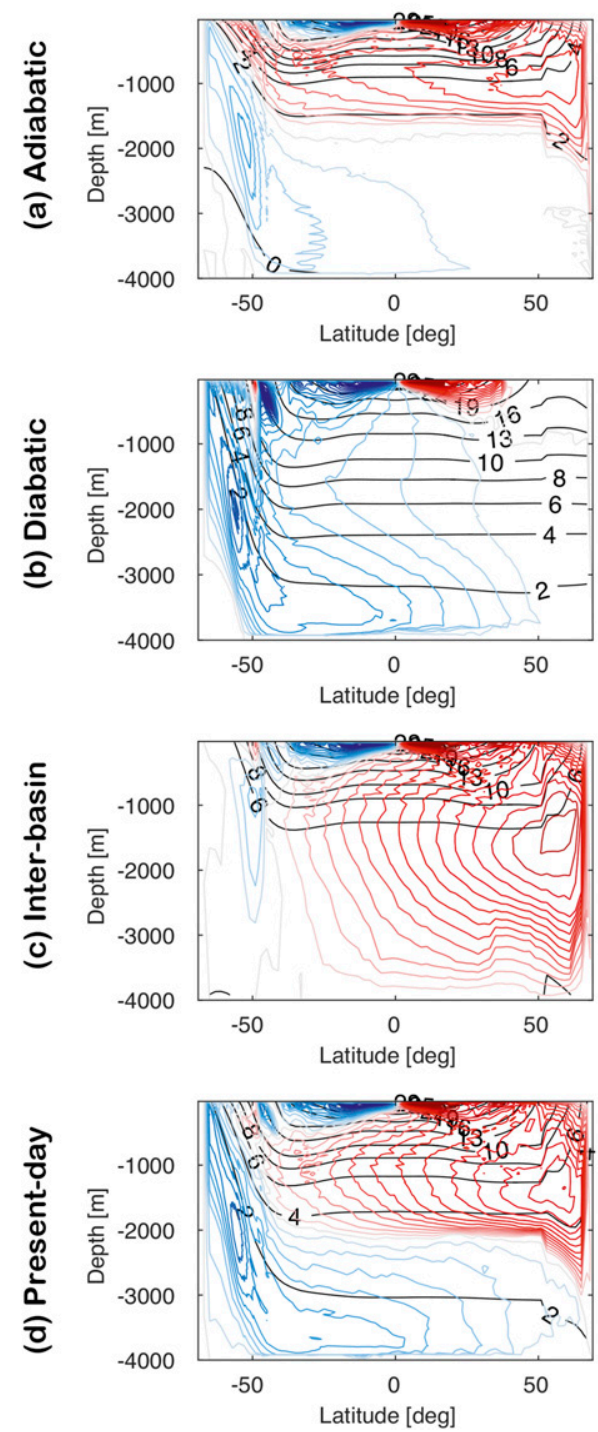

Atlantic
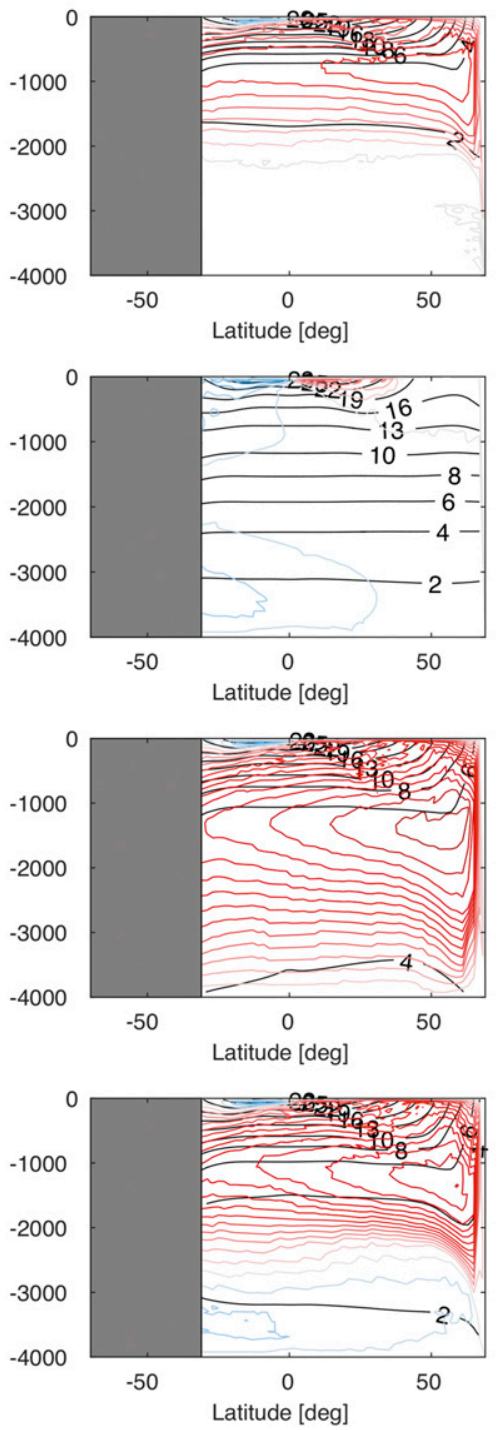

Indo-Pacific
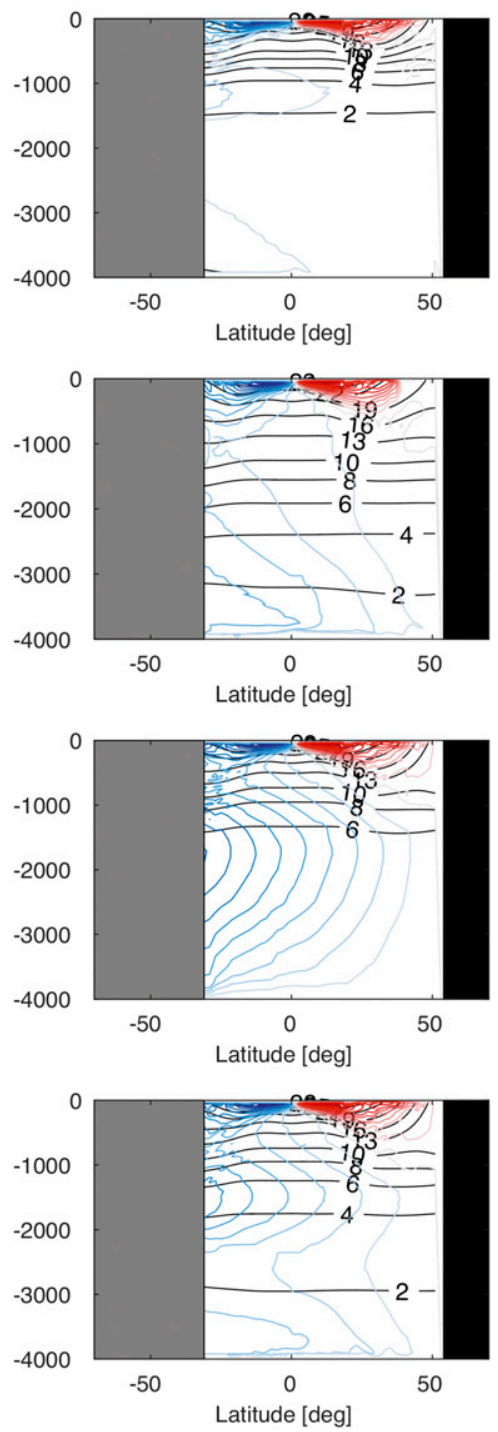

FIG. 5. Zonally averaged overturning streamfunction mapped as a function of depth, as explained in section 5, for numerical simulations representative of the four overturning circulation limits (rows). Each column shows the MOC averaged over different sectors of the model: (left) global average, (center) average over the narrow Atlantic basin, and (right) average over the wide Indo-Pacific basin. Each streamline corresponds to $2 \mathrm{~Sv}$. Black solid lines are isotherms $\left({ }^{\circ} \mathrm{C}\right)$. Black shaded areas represent landmasses and gray shading areas represent latitude bands where the basins merge and only a global streamfunction can be computed (corresponding to the latitudes south of $\phi_{P}$ in Fig. 2).

opposite direction of the deep interbasin flow. Consistent with the prediction of the theoretical model, Fig. 6a shows that isopycnals on the eastern boundary of the Atlantic basin are shallower than those on the eastern boundary of the Indo-Pacific basin. The ratio between the two depths, $\delta h / h_{P}$, is close to 0.2 as predicted by the scaling law in Eq. (20) for the geometrical parameters used in the simulation. This supports the claim that the flow into the Indo-Pacific basin at depth (and out of the basin farther up) is geostrophic. Jones and Cessi (2016) reached the same conclusion from analysis of the neutral density surfaces in the Atlantic and Pacific Oceans.

Figures $6 \mathrm{~b}$ and $6 \mathrm{c}$ further show that the transport into (out of) the narrow Atlantic basin is almost perfectly compensated by the transport out of (into) the wide Indo-Pacific basin. Thus, the picture described in section $3 \mathrm{c}$ of an interbasin exchange driven by a geostrophic flow at the southern end of the basins is supported by the numerical simulation. 

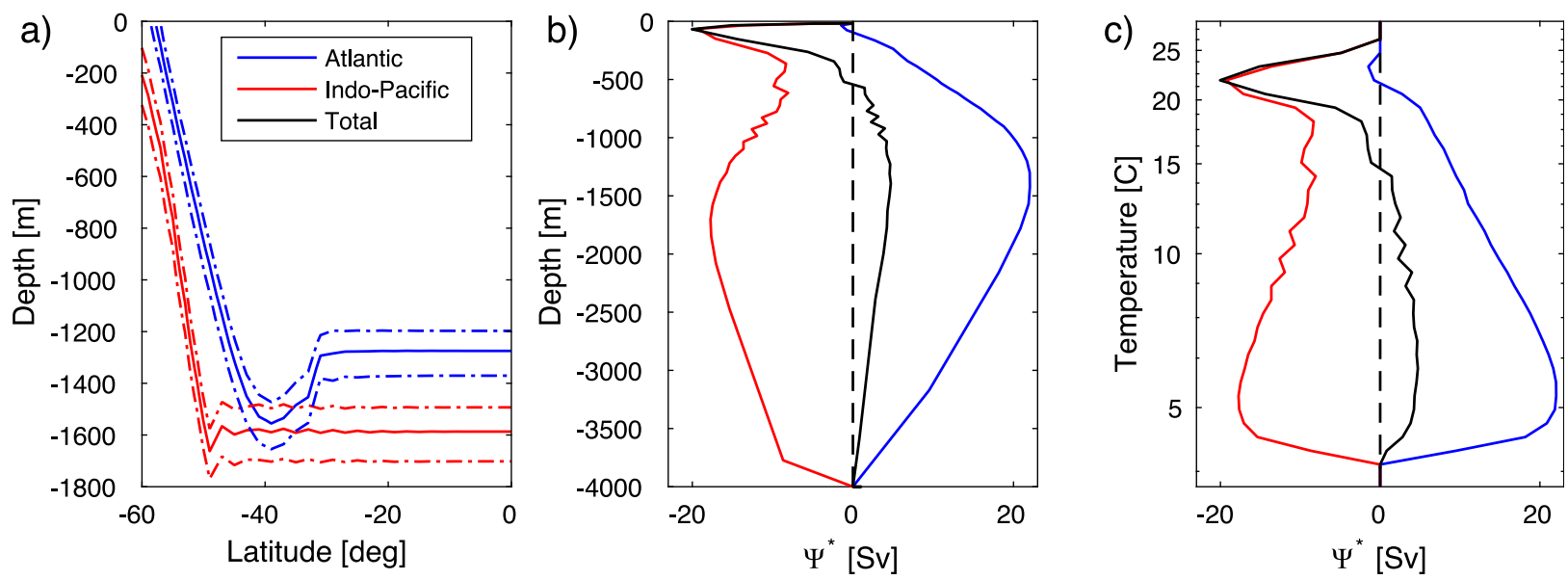

FIG. 6. Results from a simulation in the "interbasin overturning" limit, with perfect compensation of Ekman and eddy transports in the channel. (a) Isotherms (isopycnals) along the eastern boundaries of the narrow Atlantic basin (blue lines) and the wide Indo-Pacific basin (red lines). The continuous lines show the isotherms corresponding to the maximum in the MOC (see right panel), while the dashed lines show isotherms $1^{\circ}$ colder and warmer. (b),(c) The MOC computed with Eq. (22) at the south of the basin, the latitude of the model's South Africa, as a function of depth in the left panel and of temperature in the right panel. The transports are shown for zonal averages taken over different sectors: (black) global, (blue) narrow Atlantic basin, and (red) wide Indo-Pacific basin. The stratification in the lower $2000 \mathrm{~m}$ is small, and thus the lower part of the circulation is confined to within a very narrow range of temperatures.

The theory predicts that in the interbasin overturning limit, the MOC comprises a single overturning loop spanning both basins. The strength of the zonally averaged flow coming out of the Indo-Pacific basin is predicted to be equal to that entering the Atlantic and to scale with the diapycnal diffusivity according to Eq. (21). We run a series of simulations for different values of $\kappa_{V}$, and the same zero flux condition south of $36^{\circ} \mathrm{S}$. The upper-left panel of Fig. 7 shows the maxima of the MOC at the latitude of the model's South Africa, a reasonable proxy of the geostrophic transport $T_{G}$. The flow coming in and out of the two basins is very similar, confirming that waters are exchanged between the two basins rather than with the channel. Furthermore the transport does indeed increase approximately as $\kappa_{V}^{2 / 3}$ (black line) as predicted by Eq. (21).

The upper-right panel of Fig. 7 shows the depth of the isopycnal separating intermediate and deep waters in both basins as a function of $\kappa_{V}$. The isopycnal is chosen by first identifying the temperature at which the MOC peaks in each basin at the latitude of the model's South Africa (i.e., the isotherm that separates waters flowing in and out of the basins) (see Fig. 6c). The isopycnal depth is then defined as the depth of this isotherm along the eastern boundary of each basin. In practice the depth is computed over a $10^{\circ}$ longitude band along the eastern boundary and a $60^{\circ}$ latitude band centered on the equator, but the results are not very sensitive to this choice, because the isopycnal depth is pretty constant along the eastern boundary. The isopycnal depth so defined increases as $\kappa_{V}^{1 / 3}$ as predicted in Eq. (20). For all values of $\kappa_{V}$, the isopycnal is deeper in the Indo-Pacific than in the Atlantic basin, consistent with the direction of the geostrophic transport.

To further test the scaling laws in Eqs. (21) and (20), we run additional simulations with $\kappa_{V}=6 \times 10^{-5} \mathrm{~m}^{2} \mathrm{~s}^{-1}$ and a progressively larger area of the Indo-Pacific basin, $A_{P}$. The bottom panels of Fig. 7 show that both the geostrophic transport and the isopycnal depth scale with $A_{P}$ consistent with the theoretical model scalings.

Finally, it is worth remarking that the strength and vertical structure of the overturning circulation are also sensitive to the vertical profile of the diapycnal diffusivity. We only presented simulations run with a constant diapycnal diffusivity of $6 \times 10^{-5} \mathrm{~m}^{2} \mathrm{~s}^{-1}$ resulting in a vigorous overturning peaking between 1000 and $2000 \mathrm{~m}$ in both basins. We run additional simulations with a bottom-enhanced diapycnal diffusivity: the diffusivity was set to $3 \times 10^{-4} \mathrm{~m}^{2} \mathrm{~s}^{-1}$ at the ocean bottom and decayed to $3 \times 10^{-5} \mathrm{~m}^{2} \mathrm{~s}^{-1}$ at the surface with an $e$-folding scale of $1 \mathrm{~km}$, consistent with available estimates (Nikurashin and Ferrari 2013). In these simulations the overturning became somewhat weaker and more bottom trapped (not shown.) In the IndoPacific basin, the northward flow was confined below $3000 \mathrm{~m}$ and the return flow was spread uniformly between $3000 \mathrm{~m}$ and the base of the wind-driven thermoclines. Despite these differences, which are consistent with observational estimates of the ocean overturning (Lumpkin and Speer 2007), the simulations are qualitatively consistent with those with a constant diffusivity. 

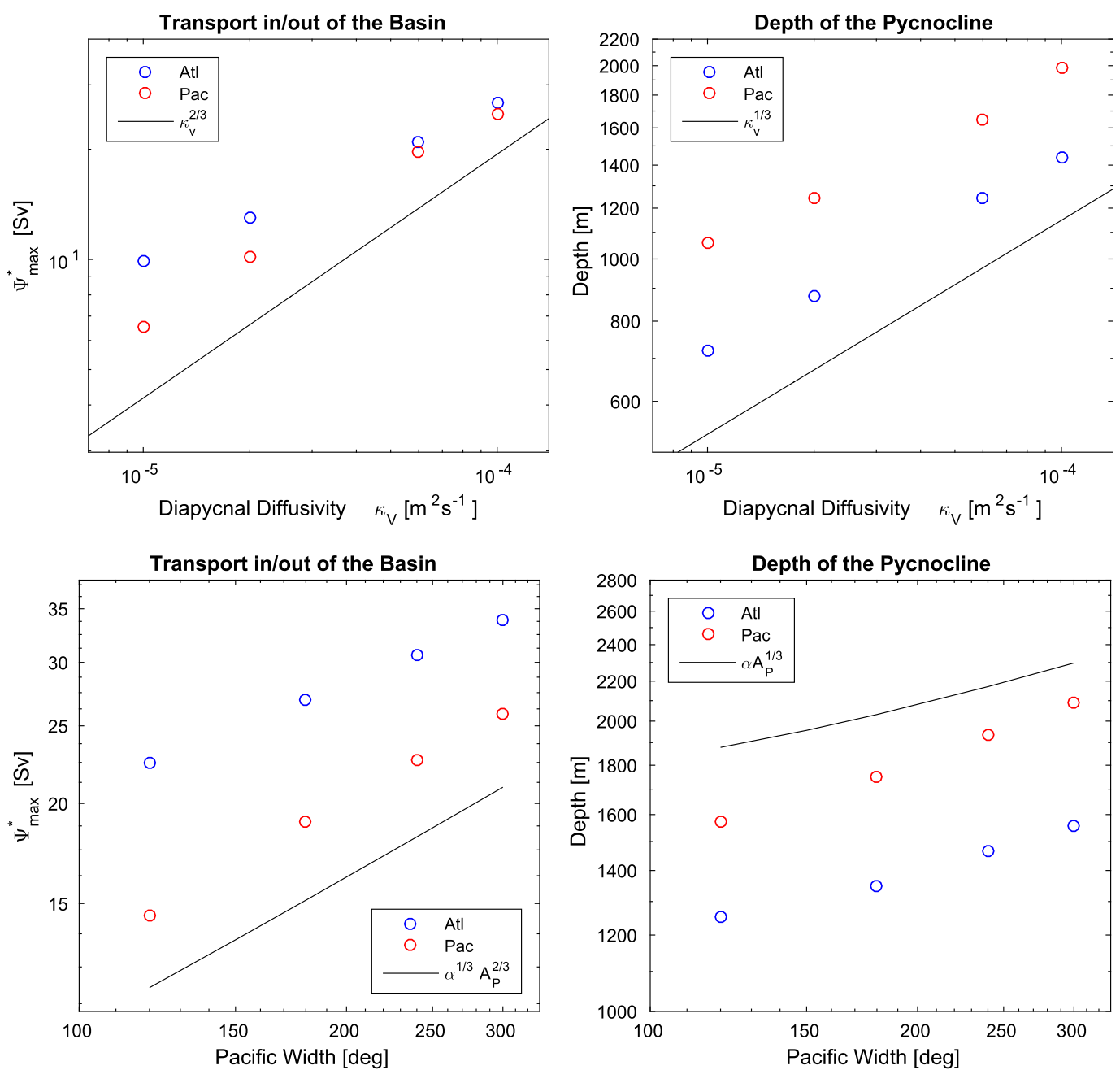

FIG. 7. (upper-left panel) Geostrophic transport in and out of both basins, estimated as the maximum of the MOC at the latitude of the model's South Africa, for different values of diapycnal diffusivity. (upper-right panel) The depth of the density surface separating deep and intermediate waters, defined as the temperature class at which the MOC peaks, along the eastern boundary of each basin. (lower-left panel) The geostrophic transport increases with the area of the wide Indo-Pacific basin as predicted by the scaling in Eq. (21). (lower-right panel) The depth of the density surface separating deep and intermediate waters scales with the area of the wide Indo-Pacific basin consistent with Eq. (20). The scalings are represented as black lines and $\alpha \equiv\left(A_{\text {tot }} / A_{P}+\left|f_{P}\right| /\left|f_{N}\right|\right)$.

\section{d. Present-day-like overturning simulation}

The relevance of the three overturning scaling regimes for the present-day ocean is now assessed with a simulation forced by somewhat realistic air-sea heat and momentum fluxes. This "reference simulation" was introduced in section 4 and uses restoring to a symmetric temperature profile in both hemispheres and $\kappa_{V}=6 \times 10^{-5} \mathrm{~m}^{2} \mathrm{~s}^{-1}$. The global MOC for this solution is shown in the bottom row of Fig. 5 and is qualitatively similar to the one calculated by Lumpkin and Speer (2007) from observations. Below shallow wind-driven gyres, the zonally averaged circulation is dominated by two counterrotating cells of similar magnitude stacked on top of each other. A middepth adiabatic cell is confined to the narrow Atlantic basin, whereas a diabatic abyssal cell spans both basins.

Two distinct MOC maxima can be seen in the bottomright panel of Fig. 5, which plots the Indo-Pacific MOC: one near the bottom around $3750 \mathrm{~m}$ and the other around $1500 \mathrm{~m}$. Two maxima can also be seen in the estimate of Lumpkin and Speer (2007), but they are not as well separated as in the simulation. The middepth adiabatic circulation in the Atlantic basin feeds the upper overturning circulation in the Indo-Pacific basin resulting in an interbasin circulation. This circulation represents a conversion from deep to intermediate 
$\mathrm{TN}=0 \mathrm{C}$
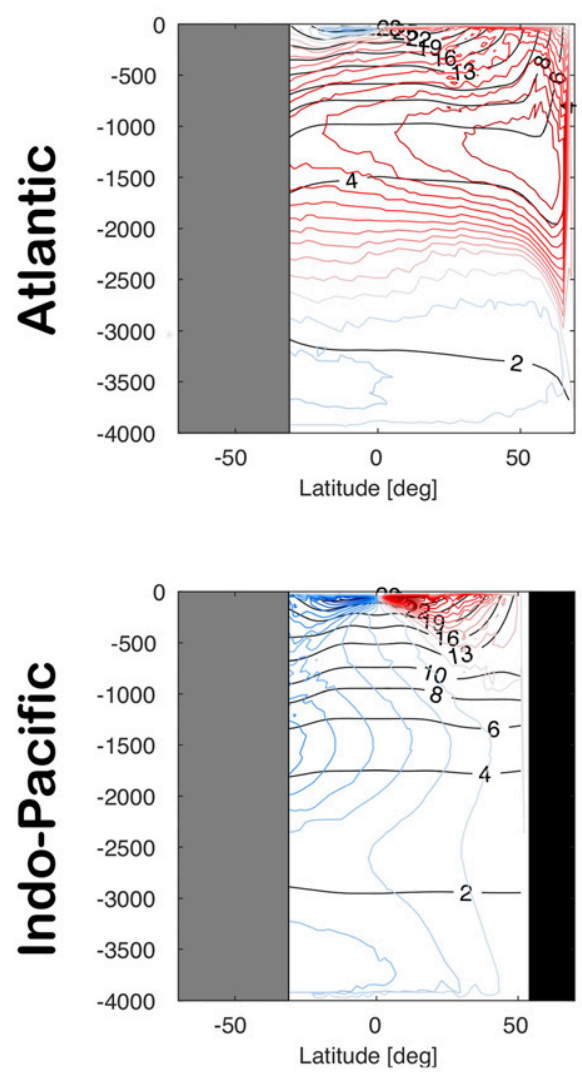

$\mathrm{TN}=-2 \mathrm{C}$
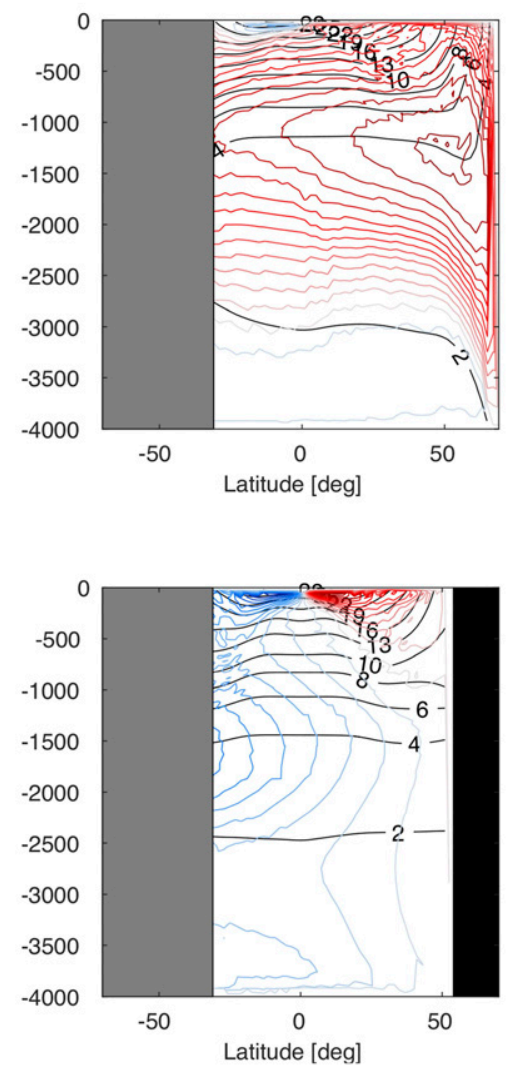

$\mathrm{TN}=-4 \mathrm{C}$
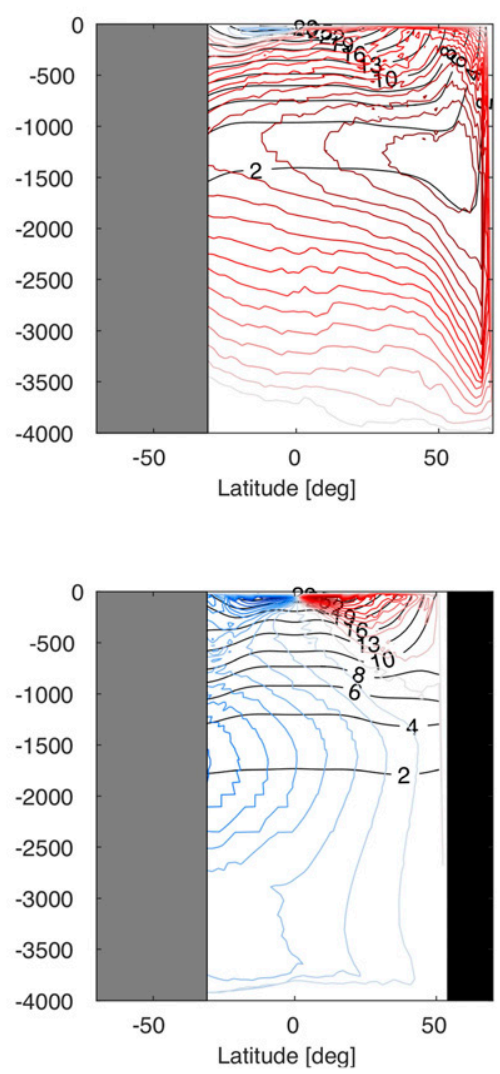

FIG. 8. Zonally averaged streamfunctions as a function of depth computed as described in section 5 for numerical simulations that are restored to different temperatures in the surface North Atlantic basin.

waters. The deeper Indo-Pacific overturning cell, which extends to the Atlantic basin as well, represents the conversion of abyssal to deep waters through mixing. This circulation is decoupled from the middepth interbasin overturning and satisfies the diabatic limit described in section $3 \mathrm{~b}$. Thus, in the Indo-Pacific basin the conversion of deep to intermediate waters satisfies the interbasin circulation, while the conversion from abyssal to deep waters follows the diabatic limit.

In the ocean, the middepth and abyssal overturning circulations largely overlap as evidenced by the lack of two very distinct maxima in the Indo-Pacific MOC (Lumpkin and Speer 2007). The overlap can be reproduced in our model by decreasing the surface density contrast between the North Atlantic basin and the channel in the Southern Hemisphere, a shortcut to capture the observation that high salinities make the North Atlantic waters denser than temperature alone can. If the restoring temperature in the North Atlantic basin is reduced, convection penetrates to deeper density classes and the two MOC maxima in the Indo-Pacific overlap and become indistinguishable as illustrated in Fig. 8. This is the figure eight loop overturning circulation that best describes the present-day ocean circulation according to Talley (2013). NADW flows adiabatically to the Southern Ocean, where it is mostly transformed into AABW, enters the Indian and Pacific Oceans to be transformed into Indian and Pacific Deep Waters by mixing, returns to the Southern Ocean to be transformed into intermediate waters that flow to the North Atlantic and close the loop. Here we have shown that such a circulation can be thought of as the combination of an adiabatic circulation in the Atlantic Ocean that converts intermediate to deep waters through convection in the north, a diabatic circulation in the Indo-Pacific Ocean that converts abyssal to deep waters through deep mixing, and an interbasin circulation that exchanges waters geostrophically between the adiabatic and diabatic basins.

\section{Conclusions}

The main contribution of this work has been to connect idealized theories of the ocean overturning circulation to the intricate pathways of water masses 
(a) Adiabatic Overturning

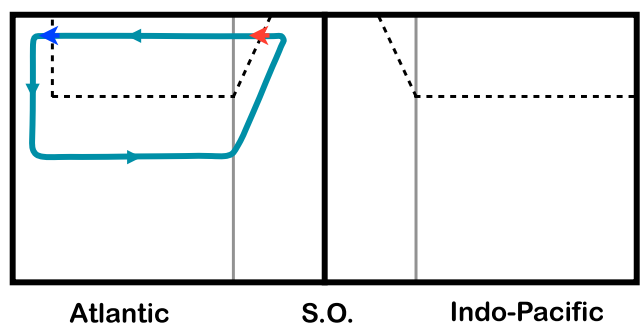

(c) Inter-basin Overturning

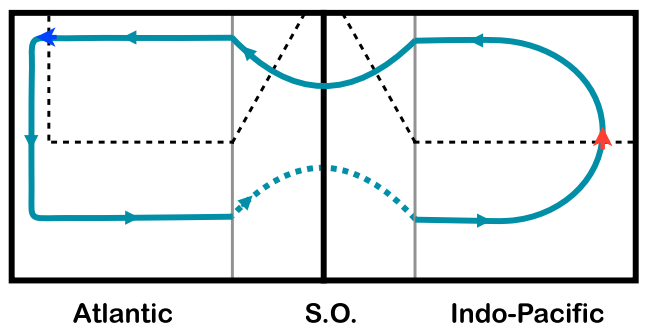

(b) Diabatic Overturning

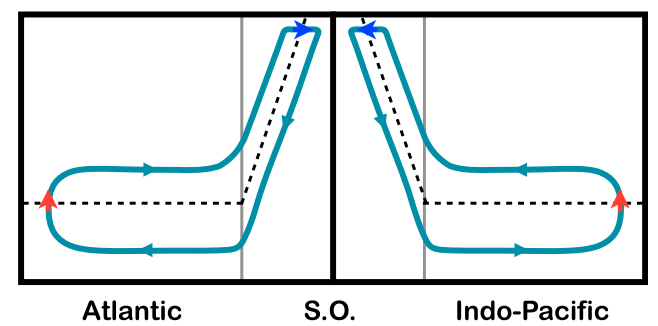

(d) Present-day Overturning

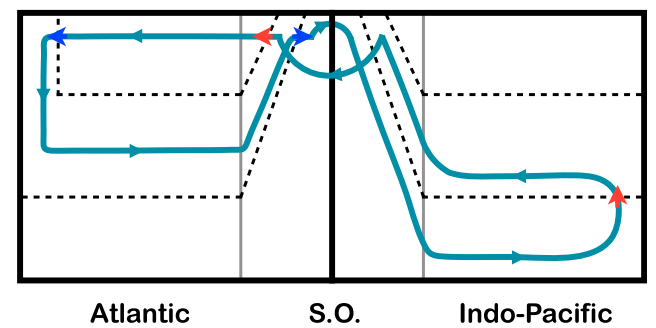

FIG. 9. Schematics of the global overturning circulation (blue loops) for the three limits described in section 3 and for the present-day ocean. For each panel the left side represents the overturning in the narrow Atlantic basin, the right side represents the overturning in the wide Indo-Pacific basin, and the center portion depicts the Southern Ocean. The arrows represent the transformation of waters by air-sea buoyancy fluxes at the surface and mixing in the interior; red (blue) arrows are for transformation into lighter (denser) waters. The dashed lines are the isopycnals that separate intermediate, deep, and abyssal waters.

generated by three-dimensional numerical models configured to capture the basic features of the ocean overturning circulation. To close the gap between idealized theories and numerical models, we considered a model with two density layers and two closed basins connected through a reentrant channel. The addition of a second basin was key to capture the different overturning circulations in the Atlantic and Indo-Pacific Oceans and it represents the main extension of previous theories (see also Jones and Cessi 2016; Thompson et al. 2016). The schematics in Figs. 9a-c illustrate the three limit circulations that are captured by such a model and were discussed in section 3. Each panel shows on the left the zonally averaged circulation in the narrow Atlantic-like basin, on the right the zonally averaged circulation in the wide Indo-Pacific-like basin, and in the middle the connection between those two circulations through a channel representing the Southern Ocean.

Figure $9 \mathrm{a}$ shows the purely adiabatic circulation that develops in the absence of any diapycnal mixing. Such a circulation is confined to the narrow Atlantic-like basin, where convection in the north converts light to dense waters and the opposite transformation occurs once waters are brought up to the surface by winds blowing over the channel. Lacking any mixing, no circulation develops in the Indo-Pacific-like basin. This is the adiabatic circulation argued to describe the upper overturning circulation cell in the Atlantic Ocean (Toggweiler and Samuels 1998; Gnanadesikan 1999). Figure 9b sketches the purely diabatic circulation that develops in the absence of convection in the North Atlantic-like basin. In this limit waters are converted from light to dense at the surface in the channel and back to light ones through mixing in the basins. This limit has been used to describe the lower overturning cells in the Atlantic and Indo-Pacific Oceans (Nikurashin and Vallis 2011). Figure 9c shows the circulation pattern that can arise in a two-basin model in the absence of any water mass transformations at the surface in the channel-this is the often considered limit where Ekman and eddy transports perfectly balance in the Southern Ocean. Dense water formed though convection in the North Atlantic-like basin flows adiabatically into the IndoPacific-like basin, where it is transformed back into lighter water through diabatic mixing, and then flows back to the Atlantic-like basin.

The ocean overturning circulation can be understood as a superposition of these three limit circulations as sketched in Fig. 9d. A minimal description of ocean water masses below the wind-driven thermoclines requires three density layers representing abyssal waters (Antarctic Bottom Water), deep waters (North Atlantic, Indian, and Pacific Deep Waters), and intermediate waters, respectively. The dominant overturning circulation in the 
Atlantic Ocean is associated with conversion of intermediate to deep waters through convection in the north. The deep waters flow adiabatically to the Southern Ocean and upwell around Antarctica in the Weddell and Ross Seas where they are converted into abyssal watersonly a small fraction of the deep waters is converted back into intermediate waters (Schmitz 1995; Lumpkin and Speer 2007; Talley 2013). The abyssal waters flow geostrophically along the seafloor in the Indian and Pacific Oceans, are transformed back into deep waters through mixing in the closed basins before returning to the Southern Ocean. There they upwell at the surface and are primarily converted into intermediate waters that flow to the North Atlantic closing the overturning loop, even though some fraction is converted back into abyssal waters. The overturning in the Atlantic Ocean is thus consistent with the adiabatic limit in Fig. 9a. This circulation is shallow and there is little mixing across the interface between deep and intermediate waters-mixing is strong only below $2000 \mathrm{~m}$, the height of most ocean ridges and rises that radiate the lee and tidal waves supporting the mixing. The overturning in the Indian and Pacific Oceans is instead consistent with the diabatic limit; the interface between deep and abyssal waters sits deeper than $2000 \mathrm{~m}$, where mixing is strong. The two circulations are connected geostrophically through the Southern Ocean as in the interbasin limit. Unlike in the interbasin limit, however, surface fluxes in the Southern Ocean transform deep to abyssal waters around Antarctica and deep to intermediate waters north of the Antarctic Circumpolar Current. (In the schematic the lower diabatic cell is entirely in the Indo-Pacific Ocean for simplicity. In the real ocean, the lower cell is found both in the Atlantic and Indo-Pacific, but it is much stronger in the latter.)

Talley (2013) infers that the bulk of North Atlantic Deep Water upwelling in the Southern Ocean is transformed into even denser Antarctic Bottom Water, rather than lighter intermediate waters. Figure $9 d$ shows that in order for this to occur, the transformation rate of intermediate to deep waters through convection in the North Atlantic must be approximately equal to the transformation rate of deep to abyssal waters around Antarctica and to the transformation rate of abyssal to deep water through mixing in the Indo-Pacific (primarily) and Atlantic (in smaller part). The observation that the amount of deep water sinking in the North Atlantic somewhat exceeds that of Antarctic Bottom Water sinking around Antarctica (Lumpkin and Speer 2007) further implies that the rate of North Atlantic sinking must slightly exceed the rate of abyssal water formation in the Southern Ocean. The two-basin model nicely captures these interbasin connections between convection in the North Atlantic and mixing in the Indo-Pacific, in addition to the more widely recognized interhemispheric connection between the surface buoyancy fluxes over the North Atlantic and the Southern Ocean, which are the main focus of zonally averaged models.

The interbasin circulation limit has not received much attention in theoretical models of the overturning circulation, which have largely focused on single-basin geometries, but it dominated early depictions of the overturning. The iconic cartoons drawn by Gordon (1986) and Broecker (1987) emphasized the flow of deep waters from the Atlantic to the Indo-Pacific Ocean and the return flow of intermediate waters at shallower depths. As in the interbasin circulation limit, the cartoons did not put much emphasis on the important water mass conversions around Antarctica, which have instead been the focus of single-basin and zonally averaged models (Marshall and Speer 2012). A full description of the circulation requires a superposition of all three idealized limits as in Fig. 9.

An interesting implication of our work is that there is a strong connection between the degree of compensation between Ekman and eddy-driven circulations in the Southern Ocean and the differences in water mass properties in the Atlantic and Indo-Pacific Oceans. With full compensation, deep and intermediate waters flow from one basin to the other without any modification. Only two water masses would fill each basin: a deep one and an intermediate one. The weaker the compensation, the larger the density differences between abyssal, deep and intermediate waters. Given that the strength of winds, heat, and salt fluxes around Antarctica have likely changed in different climates, this implies that the differences in water mass properties between the Atlantic and Indo-Pacific Oceans must have changed in response.

Thompson et al. (2016) has recently developed a multilayer, two-basin model of the overturning circulation to represent the conversions of water masses in the Southern Ocean. While more complete, the model is also more complex than the one considered here and was not amenable to analytical progress and had to be integrated numerically. Our approach has been to retain simplicity and illustrate the three circulations that when combined create the observed three-dimensional overturning. We believe that the combination of these different approaches is contributing to a better understanding of the ocean overturning circulation.

Last, but not least, the choice to represent the effect of diapycnal mixing as driving an upward mass transport across density surfaces is very incomplete. In Ferrari et al. (2016) we have shown that mixing drives both downwelling of waters in the ocean interior and upwelling along the boundaries. The description used in this manuscript holds in a zonally averaged sense for each basin, 
but at the expense of missing potentially important exchanges of waters between the ocean interior and the boundaries. The representation of isopycnal mixing generated by instabilities of large-scale flows also deserves further attention. Here we represented these eddy transports with the Gent and McWilliams (1990) parameterization, which captures only some of the gross properties of ocean instabilities. We plan to explore the implications of these physics in future work.

Acknowledgments. RF gratefully acknowledges National Science Foundation support through Awards OCE-1233832 and OCE-1536515. HLJ and DPM were supported by the NERC U.K. Overturning in the Subpolar North Atlantic Programme (OSNAP, NE/ K010948/1). LCA was supported by the Joint U.K. BEIS/Defra Met Office Hadley Centre Climate Programme (GA01101).

\section{REFERENCES}

Allison, L. C., 2009: Spin-up and adjustment of the Antarctic Circumpolar Current and the global pycnocline. Ph.D. thesis, University of Reading, $215 \mathrm{pp}$.

- H. L. Johnson, D. P. Marshall, and D. R. Munday, 2010: Where do winds drive the Antarctic Circumpolar Current? Geophys. Res. Lett., 37, L12605, https://doi.org/10.1029/ 2010 GL043355.

,-- , and -2011 : Spin-up and adjustment of the Antarctic Circumpolar Current and global pycnocline. J. Mar. Res., 69, 167-189, https://doi.org/10.1357/002224011798765330.

Broecker, W. S., 1987: The biggest chill. Nat. Hist. Mag., 97, 74-82.

Cessi, P., and C. L. Wolfe, 2009: Eddy-driven buoyancy gradients on eastern boundaries and their role in the thermocline. J. Phys. Oceanogr., 39, 1595-1614, https://doi.org/10.1175/ 2009JPO4063.1.

— , and C. S. Jones, 2017: Warm-route versus cold-route interbasin exchange in the meridional overturning circulation. J. Phys. Oceanogr., 47, 1981-1997, https://doi.org/10.1175/ JPO-D-16-0249.1.

Ferrari, R., and D. Ferreira, 2011: What processes drive the ocean heat transport? Ocean Modell., 38, 171-186, https://doi.org/ 10.1016/j.ocemod.2011.02.013.

—, M. F. Jansen, J. F. Adkins, A. Burke, A. L. Stewart, and A. F. Thompson, 2014: Antarctic sea ice control on ocean circulation in present and glacial climates. Proc. Natl. Acad. Sci. USA, 111, 8753-8758, https://doi.org/10.1073/pnas.1323922111.

_ A. Mashayek, T. J. McDougall, M. Nikurashin, and J.-M. Campin, 2016: Turning ocean mixing upside down. J. Phys. Oceanogr., 46 , 2239-2261, https://doi.org/10.1175/JPO-D-15-0244.1.

Gent, P. R., and J. C. McWilliams, 1990: Isopycnal mixing in ocean circulation models. J. Phys. Oceanogr., 20, 150-155, https:// doi.org/10.1175/1520-0485(1990)020<0150:IMIOCM > 2.0.CO;2.

Gnanadesikan, A., 1999: A simple predictive model for the structure of the oceanic pycnocline. Science, 283, 2077-2079, https://doi.org/10.1126/science.283.5410.2077.

Gordon, A. L., 1986: Interocean exchange of thermocline water. J. Geophys. Res., 91, 5037-5046, https://doi.org/10.1029/ JC091iC04p05037.
— R. F. Weiss, W. M. Smethie Jr., and M. J. Warner, 1992: Thermocline and intermediate water communication between the South Atlantic and Indian Oceans. J. Geophys. Res., 97, 7223-7240, https://doi.org/10.1029/92JC00485.

Haney, R. L., 1971: Surface thermal boundary condition for ocean circulation models. J. Phys. Oceanogr., 1, 241-248, https://doi.org/ 10.1175/1520-0485(1971)001<0241:STBCFO > 2.0.CO;2.

Johnson, H. L., and D. P. Marshall, 2004: Global teleconnections of meridional overturning circulation anomalies. J. Phys. Oceanogr., 34, 1702-1722, https://doi.org/10.1175/1520-0485(2004)034<1702: GTOMOC $>2.0 . \mathrm{CO} ; 2$.

,-- , and D. A. J. Sproson, 2007: Reconciling theories of a mechanically driven meridional overturning circulation with thermohaline forcing and multiple equilibria. Climate Dyn., 29, 821-836, https://doi.org/10.1007/s00382-007-0262-9.

Jones, C. S., and P. Cessi, 2016: Interbasin transport of the meridional overturning circulation. J. Phys. Oceanogr., 46, 11571169, https://doi.org/10.1175/JPO-D-15-0197.1.

Lumpkin, R., and K. Speer, 2007: Global ocean meridional overturning. J. Phys. Oceanogr., 37, 2550-2562, https://doi.org/ 10.1175/JPO3130.1.

Luyten, J., J. Pedlosky, and H. Stommel, 1983: Climatic inferences from the ventilated thermocline. Climatic Change, 5, 183-191, https://doi.org/10.1007/BF00141269.

Marotzke, J., 1997: Boundary mixing and the dynamics of threedimensional thermohaline circulations. J. Phys. Oceanogr., 27, 1713-1728, https://doi.org/10.1175/1520-0485(1997)027<1713: BMATDO $>2.0 . \mathrm{CO} ; 2$.

Marshall, J., and K. Speer, 2012: Closure of the meridional overturning circulation through Southern Ocean upwelling. Nat. Geosci., 5, 171-180, https://doi.org/10.1038/ngeo1391.

— A. Adcroft, C. Hill, L. Perelman, and C. Heisey, 1997: A finite-volume, incompressible Navier Stokes model for studies of the ocean on parallel computers. J. Geophys. Res., 102, 5753-5766, https://doi.org/10.1029/96JC02775.

Munday, D. R., L. C. Allison, H. L. Johnson, and D. P. Marshall, 2011: Remote forcing of the Antarctic Circumpolar Current by diapycnal mixing. Geophys. Res. Lett., 38, L08609, https:// doi.org/10.1029/2011GL046849.

Munk, W. H., 1966: Abyssal recipes. Deep-Sea Res. Oceanogr. Abstr., 13, 707-730, https://doi.org/10.1016/0011-7471(66)90602-4.

Nikurashin, M., and G. Vallis, 2011: A theory of deep stratification and overturning circulation in the ocean. J. Phys. Oceanogr., 41, 485-502, https://doi.org/10.1175/2010JPO4529.1.

_, and - 2012: A theory of the interhemispheric meridional overturning circulation and associated stratification. J. Phys. Oceanogr., 42, 1652-1667, https://doi.org/10.1175/JPO-D-11-0189.1.

-, and R. Ferrari, 2013: Overturning circulation driven by breaking internal waves in the deep ocean. Geophys. Res. Lett., 40, 3133-3137, https://doi.org/10.1002/grl.50542.

Nurser, A., and M.-M. Lee, 2004: Isopycnal averaging at constant height. Part II: Relating to the residual streamfunction in Eulerian space. J. Phys. Oceanogr., 34, 2740-2755, https://doi.org/ 10.1175/JPO2650.1.

Rintoul, S. R., 1991: South Atlantic interbasin exchange. J. Geophys. Res., 96, 2675-2692, https://doi.org/10.1029/90JC02422.

Roe, P. L., 1985: Some contributions to the modeling of discontinuous flows. Large-Scale Computations in Fluid Mechanics, B. Engquist, S. Osher, and R. Somerville, Eds., American Mathematical Society, 163-193.

Schmitz, W. J., 1995: On the interbasin-scale thermohaline circulation. Rev. Geophys., 33, 151-173, https://doi.org/10.1029/ 95RG00879. 
Talley, L. D., 2013: Closure of the global overturning circulation through the Indian, Pacific, and Southern Oceans: Schematics and transports. Oceanography, 26, 80-97, https://doi.org/ 10.5670/oceanog.2013.07.

Thompson, A. F., A. L. Stewart, and T. Bischoff, 2016: A multibasin residual-mean model for the global overturning circulation. J. Phys. Oceanogr., 46, 2583-2604, https://doi.org/10.1175/ JPO-D-15-0204.1.

Toggweiler, J. R., and B. Samuels, 1998: On the ocean's large-scale circulation near the limit of no vertical mixing. J. Phys. Oceanogr., 28, 1832-1852, https://doi.org/10.1175/1520-0485(1998)028<1832: OTOSLS $>2.0$.CO;2.

Veronis, G., 1973: Model of world ocean circulation: 1. Winddriven, two-layer. J. Mar. Res., 31, 228-288.

_ 1976: Model of world ocean circulation: 2 . Thermally driven, two-layer. J. Mar. Res., 34, 199-216.
1978: Model of world ocean circulation: 3. Thermally and wind driven. J. Mar. Res., 36, 1-44.

Warren, B. A., 1983: Why is no deep water formed in the North Pacific? J. Mar. Res., 41, 327-347, https://doi.org/10.1357/ 002224083788520207.

Weaver, A., C. Bitz, A. Fanning, and M. Holland, 1999: Thermohaline circulation: High-latitude phenomena and the difference between the Pacific and Atlantic. Annu. Rev. Earth Planet. Sci., 27, 231285, https://doi.org/10.1146/annurev.earth.27.1.231.

Welander, P., 1986: Thermohaline effects in the ocean circulation and related simple models. Large-Scale Transport Processes in the Oceans and Atmosphere, J. Willebrand and D. L. T. Anderson, Eds., D. Riedel, 163-200.

Wolfe, C. L., and P. Cessi, 2011: The adiabatic pole-to-pole overturning circulation. J. Phys. Oceanogr., 41, 1795-1810, https:// doi.org/10.1175/2011JPO4570.1. 